\title{
РАСПРЕДЕЛЕНИЕ ПЛОЩАДИ ЗЕМЕЛЬНЫХ УЧАСТКОВ КЕРЕБЕЛЯКСКОГО ЛЕСНИЧЕСТВА НАЦИОНАЛЬНОГО ПАРКА «МАРИЙ ЧОДРА»
}

\author{
П.М. Мазуркин ${ }^{1}$, Н.Г. Эльтерова ${ }^{2}$, \\ ${ }^{1}$ Доктор технических наук, профессор, академик ЕАЕ, РАЕ и РАЕН, \\ зав. кафедрой природообустройства, kaf_po@ mail.ru, \\ ${ }^{2}$ магистрант 2 курса по направлению 20.04.01 «Техносферная безопасность» \\ направленности «Охрана природной среды особо охраняемых территорий», \\ Поволжский государственный технологический университет, \\ Йошкар-Ола, Республика Марий Эл, Россия
}

\begin{abstract}
Рассмотрены общие закономерности в виде суммы вейвлет-сигналов распределения численности лесных земельных участков на всех лесных кварталах Керебелякского лесничества национального парка «Марий Чодра» по одинаковой площади, а также ранговое распределение площади лесных земельных участков. Доказано, что распределение количества лесных земельных участков одной площади показывает дробление территории лесных выделов, а ранговое распределение площади лесных земельных участков показывает многочисленные антропогенные воздействия. Для эвристической идентификации этих воздействий нужно будет сравнить выявленные в статье закономерности с теми волновыми формулами, которые будут получены по распределениям лесных земельных участков девственных лесов.
\end{abstract}

Ключевые слова: лесные земельные участки, численность, площадь, ранговые распределения, вейвлет анализ, волновые закономерности

\section{DISTRIBUTION AREA LAND KOBELYAKY FORESTRY NATIONAL PARK "MARIY CHODRA"}

${ }^{1}$ P. M. Mazurkin, ${ }^{2}$ N.G. Elterova

${ }^{1}$ Doctor of Technical Sciences, Professor, Department of environmental engineering,

${ }^{2}$ the 2-year student 20.04.01 in the direction of "Technosphere safety"

direction "Protection of natural environment protected areas",

Volga State University of Technology, Yoshkar-Ola, Republic of Mari El, Russian Federation

Corresponding author: kaf_po@mail.ru

The general pattern as the sum of the wavelet signals forest land allocation on the number of forest blocks Kerebelyakskogo forest national park "Mari Chodra" in the same area, as well as the rank distribution area of forest land. We prove that the distribution of the number one area of forest land shows the fragmentation of forest stands, and rank distribution area of forest land features numerous human impacts. For heuristic identification of these impacts will need to compare the patterns identified in the article with the wave formulas to be derived from distributions of forest land of virgin forests.

Keywords: forest land, population, area, rank distributions, wavelet analysis, the wave patterns

Введение. Из всех четырех лесничеств национального парка «Марий Эл» особого внимания к моделированию распределений всех лесных земельных участков и лесных выделов (лесных земельных участков, на ко- 
торых расположены лесные деревья), а также таксационных показателей этих лесных выделов, требует Керебелякское лесничество.

Метод идентификации закономерностей. Подробнее отдельные особенности предложенной методологии даны в статьях [3-5, 9-12]. Технология пользования программной средой CurveExpert-1.40 показана в пособиях $[1,2,6-8]$.

Идентификация по числовому полю (табличной модели) имеет этапы:

1) эвристическая идентификация сути изучаемого явления или процесса по результатам измерений и анализа табличной модели (априорная информация) и осмысления в ходе выявления конструкции у однофакторной закономерности по её аддитивным составляющим (апостериорная информация);

2) структурная идентификация каждой однофакторной математической (статистической) детерминированной или волновой функции как суммы инвариантов в виде асимметричных вейвлет-сигналов с переменными амплитудой и периодом колебания;

3) параметрическая идентификация наращиваемой по отдельным инвариантам структуры устойчивой статистической закономерности в программной среде типа CurveExpert (http://www.curveexpert.net).

Идентификация эвристическая. Она предполагает знание предмета исследования, поэтому здесь важен переход от физики к математике, а не наоборот. Главное эвристическое значение приобретает заданное числовое поле, как правило, оформляемое по результатам измерений в виде таблицы. В ней неявно заключен весь содержательный смысл (эвристика) и понимание (концепция) автора измерений, то есть сущностный смысл эксперимента. Таксационные описания составляются в России примерно через 10 лет, а в развитых лесных странах они уточняются ежегодно.

Мы давно отказались от методологии аппроксимации табличной модели произвольными уравнениями и, соответственно, вообще не применяем программы статистики из программной среды Excel.

В идентификации первый этап (вариация функций) из теории аппроксимации исключается, - устойчивые законы заранее заданы как инварианты. Из них как из кирпичиков можно создавать различные математические конструкты. Использование в каждом конкретном примере статистического (вероятностного) моделирования того или иного устойчивого закона (по таблице 1 их всего семь) требует предварительного эвристического осмысления содержания задачи моделирования.

Таким образом, на эвристическом уровне 23-я проблема Гильберта нами пока недостаточно формализована. Но проблема развития методов вариационного исчисления пока решена только на структурном и параметрическом уровнях анализа и синтеза. Вариация функций сводится к осознанному отбору устойчивых законов и конструированию на их основе волновых закономерностей. Эвристический этап остается за человеком. 
Идентификация структурная. Декарт предполагал существование одного-единственного алгебраического уравнения, пригодного как вариант решения для любых типов интегральных уравнений. Гильберт мечтал об инвариантах, из них как из кирпичиков будет собираться универсальное уравнение.

Наши универсальные инварианты даны в таблице 1.

Таблица 1. Математические конструкты (исходные инварианты

или кирпичики Гильберта) для составления статистической модели

\begin{tabular}{|c|c|}
\hline $\begin{array}{c}\text { Фрагменты без предыстории } \\
\text { изучаемого явления или процесса }\end{array}$ & $\begin{array}{c}\text { Фрагменты с предысторией } \\
\text { изучаемого явления или процесса }\end{array}$ \\
\hline $\begin{array}{l}a x \text { - закон линейного роста или спада } \\
\text { и отрицательном знаке перед правой } \\
\text { роной формулы линейного изменения) }\end{array}$ & $\begin{array}{l}y=a-\text { - закон не влияния принятой объяс- } \\
\text { няющей переменной на показатель, кото- } \\
\text { рый имеет собственную предысторию зна- } \\
\text { чений }\end{array}$ \\
\hline $\begin{array}{l}y=a x^{b} \text { - закон показательного роста (закон } \\
\text { показательной гибели } y=a x^{-b} \text { не является } \\
\text { устойчивым, из-за бесконечности значения } \\
\text { показателя при нулевом значении объяс- } \\
\text { няющей переменной) }\end{array}$ & $\begin{array}{l}y=a \exp ( \pm c x) \text { - закон Лапласа в матема- } \\
\text { тике (Ципфа в биологии, Парето в эконо- } \\
\text { мике, Мандельброта в физике) экспонен- } \\
\text { циального роста или гибели, относительно } \\
\text { которого } \\
\text { Лаплас создал методологию операторного } \\
\text { исчисления }\end{array}$ \\
\hline $\begin{array}{l}y=a x^{b} \exp (-c x) \text { - биотехнический закон в } \\
\text { упрощенной форме (П.М. Мазуркин), ко- } \\
\text { гда показательный рост постепенно полу- } \\
\text { чает экспоненциальное торможение }\end{array}$ & $\begin{array}{l}y=a \exp \left( \pm c x^{d}\right) \text { - закон экспоненциального } \\
\text { роста или гибели в полной форме (конст- } \\
\text { рукции), который имеет интенсивность, не } \\
\text { равную единице (П.М. Мазуркин) }\end{array}$ \\
\hline \multicolumn{2}{|c|}{$\begin{array}{c}y=a x^{b} \exp \left(-c x^{d}\right) \text { - биотехнический закон, общий для шести конструктов (П.М. Ма- } \\
\text { зуркин) }\end{array}$} \\
\hline
\end{tabular}

Кирпичики Гильберта сгруппированы по принципу «от простого к сложному». По сути, фрагменты и сам биотехнический закон являются «кирпичиками Гильберта» для построения, в ходе процесса структурнопараметрической идентификации, аддитивной конструкции статистической модели с трендами и вейвлетами.

Инварианты колебательных возмущений в виде асимметричных вейвлет-сигналов также включают в себя конструкты из таблицы 1 как амплитуда (половина) и полупериод.

В таблице 1 показаны наиболее встречающиеся инварианты (фрагменты). У них впереди могут быть расположены оперативные константы «+» или «-». Шесть устойчивых законов распределения являются частными случаями биотехнического закона, показанного внизу таблицы 1 . В названии закона слово «биотехнический» означает, что мы придерживаемся идей В.И. Вернадского о космической функции жизни. Это доказывается в тем, что ряд Фибоначчи является неким «родственником» ряда положительных простых чисел.

Если известны эвристическая предыстория формирования числового 
поля (табличной модели), то вполне возможна смысловая расшифровка каждого вейвлет-сигнала в череде в виде суммы сигналов, у которого вейвлет (волновая функция) в своей конструкции содержит те или иные математические инварианты из таблицы 1.

Устойчивые законы и закономерности на их основе делают выбор уравнения для последующей идентификации на статистических данных (числовых полях) вполне осмысленным, и поэтому вероятностное моделирование остается только при случайном поиске программной средой типа CurveExpert-1.40 значений параметров у искомой модели. Поэтому из теории идентификации первый этап (выбор случайной структуры уравнения) исключается и остается только второй этап - случайная идентификация значений параметров модели.

Структура модели идентифицируется обработкой данных так:

- вначале выявить детерминированные нелинейные закономерности;

- затем дополнять эти тренды колебательными возмущениями.

Идентификация параметрическая. Она выполнялась в программной среде CurveExpert-1.40 (http://www.curveexpert.net) и информационной технологией идентификации пользуются студенты (будущие бакалавры и магистры), а также аспиранты и докторанты. На сквозных примерах методология структурно-параметрической идентификации подробно показана в книгах [1, 2, 6-8].

Выбор структуры искомой модели, которая является алгебраическим решением по Декарту для неизвестной первообразной по волновым уравнениям, имеющим переменные амплитуду и полупериод (половины частоты как обратная величина полупериода) колебательного возмущения объекта исследования, выполняется из устойчивых законов (инвариантов), приведенных в таблице 1 .

Процесс параметрической идентификации автоматически прекращается по условию достижения параметров модели некоторого минимального приращения и останавливается исследователем при достижении наращиваемой моделью погрешности измерений.

Уровни адекватности закономерностей. В таблице 2 приведены интервалы коэффициента корреляции как меры адекватности модели.

Существующая шкала квантификации тесноты связи между принятыми факторами (нет связи, слабая и сильная связь) является очень грубой.

Критерием (количественной мерой) идентификации становится погрешность измерений при составлении числового поля, т.е. таблицы исходные данных. Например, простые числа и их ряды не имеют погрешности измерения: они абсолютно достоверны, добротны и надежны. Другие виды исходных данных имеют разную погрешность. Математические числовые объекты - наилучшие для идентификации законов-инвариантов.

На втором месте находятся прецизионные измерения в астрономии, физике, технике и технологии, других областях науки. 
Таблица 2. Уровни адекватности статистических моделей

\begin{tabular}{|c|c|c|c|c|}
\hline \multirow[b]{2}{*}{$\begin{array}{c}\text { Интервал ко- } \\
\text { эффициента } \\
\text { корреляции }\end{array}$} & \multicolumn{4}{|c|}{ Характер тесноты связи между факторами } \\
\hline & $\begin{array}{l}\text { существующая } \\
\text { классификация }\end{array}$ & $\begin{array}{c}\text { шкала для } \\
\text { технических } \\
\text { измерений } \\
\end{array}$ & \begin{tabular}{|c|} 
шкала для \\
прецизионных \\
измерений \\
\end{tabular} & $\begin{array}{c}\text { шкала для генной } \\
\text { инженерии и рядов } \\
\text { целых простых чисел }\end{array}$ \\
\hline 1 & \multirow{6}{*}{ сильная связь } & однозначная & однозначная & однозначная \\
\hline $0.999 \ldots 1.0000$ & & \multirow{4}{*}{ сильнейшая } & почти & почти однозначная \\
\hline $0,99 \ldots 1,000$ & & & однозначная & чрезвычайно сильная \\
\hline $0,95 \ldots 0,99$ & & & сверхсильная & сверхсильная \\
\hline $0,90 \ldots 0,95$ & & & сильнейшая & сильнейшая \\
\hline $0,7 \ldots 0,9$ & & сильная & сильная & сильная \\
\hline $0,5 \ldots 0,7$ & \multirow{2}{*}{ слабая связь } & средняя & средняя & средняя \\
\hline $0,3 \ldots 0,5$ & & слабоватая & слабоватая & слабоватая \\
\hline $0,1 \ldots 0,3$ & \multirow{3}{*}{ нет связи } & слабая & Слабая & слабая \\
\hline $0,0 \ldots 0,1$ & & слабейшая & слабейшая & слабейшая \\
\hline 0 & & нет связи & нет связи & нет связи \\
\hline
\end{tabular}

На третье место встают биологические объекты (у нас - почва [2] и деревья [4], древостои [1,3] и земельные участки [7]), и их поведение имеет четко проявляющийся колебательный характер, поэтому линейные и линеаризованные модели биологам вообще не подходят.

Самые высокие погрешности имеют социально-экономические измерения $[6,8]$ из-за их субъективности.

Нами было доказано, что анализ слабых связей, отбрасываемых при линейном моделировании, и применении среднеарифметической факторной связи по закону Гаусса (нормального распределения), дает новые научные идеи и последующие научно-технические решения (за 10 лет с участием студентов было получено более 110 патентов на изобретения РФ).

Анализ литературы по математической статистике показал, что в аппроксимации сплошь и рядом применяется линейная модель или же не имеющий физического смысла алгебраический полином. Это происходит из-за того, что линейная модель инвариантна к любому типу распределения и к отрицательным значениям объясняющей переменной, в том числе и явно негауссовой структуры, и даже к скедастическим данным измерений с переменной дисперсией.

Нами предложена для технических экспериментов, в которых погрешность измерений не превышает 5\%, другая шкала (третий столбец таблицы 2). Однако выяснилось, что этой шкалы уровней адекватности также недостаточно для верификации выявленных закономерностей.

Для многих природных (биологических) объектов и результатов прецизионных физических измерений пришлось ввести еще два интервала уровня адекватности по четвертому столбцу таблицы 1 , что нами было выполнено только при моделировании распределений рядов простых чисел [1]. А для генной инженерии, по данным статьи (Jayodita C Sanghvil et al. Accelerated discovery via a whole-cell model. Nat. Methods. Published online 3 
November 2013 | doi:10.1038/nmeth.2724), пришлось ввести еще один уровень адекватности, который нами был открыт только для популяций генов и рядов целых простых чисел.

Концепция моделирования по статистическим выборкам. Статистическая выборка - это многофакторное числовое поле в виде табличной модели. Этим определением она отличается от таблиц статистических изысканий. Причем необязательно все клетки таблицы должны быть заполненными, хотя это затрудняет формирование бинарных отношений.

При этом табличная модель необязательно имеет эвристические пояснения. Как правило, авторы измерений, приводя в своих публикациях таблицы данных, дают неверные содержательные толкования. Этот феномен эвристической формализации связан с тем, что таблица результатов измерений, даже если она составлена авторами правильно, не может быть содержательно осмыслена без проведения факторного анализа $[6,8]$ с математическим моделированием связей между парами факторов для выявления бинарных связей.

Тогда первичной становится табличная модель (исходное числовое поле), которая оценивается по погрешности проведенных измерений, а вторичным является искомое сложное алгебраическое уравнение (в смысле Декарта), составленное из инвариантов таблицы 1 (в смысле кирпичиков Гильберта). Этот процесс есть статистическая идентификация.

Сама первообразная в виде неизвестного интегрального уравнения становится не нужным, хотя, может быть, кто-то и сумеет получать интегралы по нашим моделям. Это будет великое созидание, как уравнения Максвелла в электромагнетизме.

Детерминированная модель. В общем случае не волновая модель (тренд) содержит сумму двух биотехнических законов в виде уравнения

$y_{m}=y_{m 1}+y_{m 2}, y_{m 1}=a_{1} x^{a_{2}} \exp \left(-a_{3} x^{a_{4}}\right), y_{m 2}=a_{5} x^{a_{6}} \exp \left(-a_{7} x^{a_{8}}\right)$,

где $y_{m}-$ тренд,

$x$ - объясняющая переменная,

$a_{1} \ldots a_{8}$ - параметры модели (1).

При этом каждый параметр модели (1) имеет физический смысл [6].

Не волновой характер общая модель (1) получает в двух случаях:

1) когда шаг дискретности измерений слишком большой по сравнению с периодом колебательного возмущения измеряемого реального процесса (например, импульс электрокардиограммы требует регистрации через $0,001 \mathrm{c})$;

2) когда интервал процесса измерений мал по сравнению с полупериодом колебательного возмущения измеряемого показателя (например, среднегодовая температура в точке Земли требует регистрации за 1000 лет и более).

Модель типа (1) появляется, как правило, при длинных волнах. 
Асимметричный вейвлет. Мы придерживаемся концепции Декарта о необходимости применении алгебраического уравнения общего вида напрямую как конечного математического решения неизвестных интегральных уравнений. Для обобщения был предложен новый класс волновых функций [1-12].

Для идентификации искомых волновых закономерностей по известным табличным моделям достаточна усеченная конструкция (по формуле частоты колебания) асимметричного вейвлета [8-12] типа

$$
\begin{aligned}
y=\sum_{i=1}^{m} y_{i}, y_{i} & =A_{i} \cos \left(\pi x / p_{i}-a_{8 i}\right), \\
A_{i}=a_{1 i} x^{a_{2 i}} \exp \left(-a_{3 i} x^{a_{4 i}}\right), p_{i} & =a_{5 i}+a_{6 i} x^{a_{7 i}},
\end{aligned}
$$

где $A_{i}$ - амплитуда (половина) вейвлета (ось $y$ ),

$p_{i}$ - полупериод волны (ось $x$ ),

$y$ - показатель (зависимый фактор),

$i$ - номер составляющей модели (2),

$m$ - количество членов в модели (2),

$x$ - объясняющая переменная (влияющий фактор),

$a_{1} \ldots a_{8}$ - параметры модели, принимающие числовые значения в ходе структурно-параметрической идентификации в специальной программной среде (URL: http://www.curveexpert.net/) по мере увеличения коэффициента корреляции при наращивании количества составляющих статистической модели (2). При этом количество $m$ членов в наших примерах достигала до 120 и более.

Как правило, общая стохастическая волновая функция (2), в которой не волновые части (1) становятся частными случаями и показывают детерминированное на интервале времени измерений поведение объекта исследования. Это позволяет идентифицировать составной статистической моделью поведение многих математических, астрономических, биологических и экологических, социально-экономических и иных объектов.

Динамический ряд как череда сигналов. Физико-математический подход предполагает понимание смысла динамического ряда как отражения какого-то составного процесса или же множества последовательно и параллельно происходящих природных и/или природно-антропогенных процессов. При этом череда понимается как процесс суммирования.

Впервые удалось получать модели многих типов рядов динамики [112] на концепции аддитивного разложения любого динамического ряда на множество вейвлет-сигналов.

Сигнал - это материальный носитель информации. А информация нами понимается как мера взаимодействия. Сигнал может генерироваться, но его приём не обязателен. Так, например, ряд простых чисел известен несколько тысяч лет, но суть его как множества сигналов до сих пор не 
была раскрыта. Сигналом может быть любой физический процесс или его часть. Получается, что изменение множества неизвестных сигналов давно известно, например, через ряды гидрометеорологических измерений во многих точках планеты. Однако до сих пор не получены их статистические модели динамики.

По формуле (2) с двумя фундаментальными физическими постоянными $e$ (число Непера или число времени) и $\pi$ (число Архимеда или число пространства) образуется изнутри изучаемого явления и/или процесса квантованный вейвлет-сигнал. Понятие асимметричного вейвлетсигнала позволяет абстрагироваться от физического смысла самих динамических рядов. В общем случае не только динамических, но и других типов статистических рядов, и рассматривать их аддитивное разложение.

Исходные данные. Нами из таблиц «Таксационное описание (по состоянию на 01.01.05 года)» на 665 стр. из файла tak-01n.doc по Керебелякскому лесничеству НП «Марий Чодра» были составлены табличные модели для последующей структурной и параметрической идентификации.

Численность лесных земельных участков. В таблице 3 представлен фрагмент исходных данных по численности $N$ лесных земельных участков (ЗУ) при одинаковом значении площади $S$ этих ЗУ на территории Керебелякского лесничества национального парка «Марий Чодра».

Таблица 3. Влияние площади

на количество лесных

земельных участков

\begin{tabular}{|c|c|c|}
\hline $\begin{array}{c}\text { № } \\
\text { п/п }\end{array}$ & $\begin{array}{c}\text { Площадь } \\
S, \text { га }\end{array}$ & $\begin{array}{c}\text { Кол-во 3У } \\
N, \text { шт. }\end{array}$ \\
\hline 1 & 187 & 1 \\
\hline 2 & 161 & 1 \\
\hline 3 & 157 & 1 \\
\hline 4 & 145 & 1 \\
\hline 5 & 144 & 1 \\
\hline$\ldots$ & $\ldots$ & $\ldots$ \\
\hline 279 & 0.7 & 98 \\
\hline 280 & 0.6 & 127 \\
\hline 281 & 0.5 & 86 \\
\hline 282 & 0.4 & 153 \\
\hline 283 & 0.3 & 110 \\
\hline 284 & 0.2 & 141 \\
\hline 285 & 0.1 & 86 \\
\hline
\end{tabular}

При значениях площади ЗУ от 187 до 128 га наблюдается всего по одному лесному земельному участку. Затем от 187 до 79 га появляется небольшая флюктуация среди 1 до численности, равной 7. С площади 69 га и менее до 21,5 га снова наблюдаются 1 . После 21.3 га и менее до 10,8 га снова наблюдается флуктуация до количества 5. И только после площади меньше 11,3 га все значения численности ЗУ превышают 1.

Тогда минимальная численность лесных $3 У$ равна $N_{\min }=1$. А максимальная численность $N_{\max }=153$ достигается при площади в 0,4 га.

Таким образом, распределение численности земельных участков при одинаковой

их площади характеризуются сложной математической функцией.

После идентификации модели (2) получена (рис. 1) формула тренда

$$
N=1+3.43596 \cdot 10^{9} S^{2.59045} \exp \left(-17.61848 S^{0.18986}\right) \text {. }
$$

Это уравнение по данным таблицы 2 соответствует биотехническому закону проф. П.М. Мазуркина. Он показывает, что при нулевой площади теоретически существует всего один земельный участок, на котором по- 
тенциально могут произрастать лесные деревья. В интервале от 0 до 0,1 га могут существовать намного меньше 86 штук лесных земельных участков.

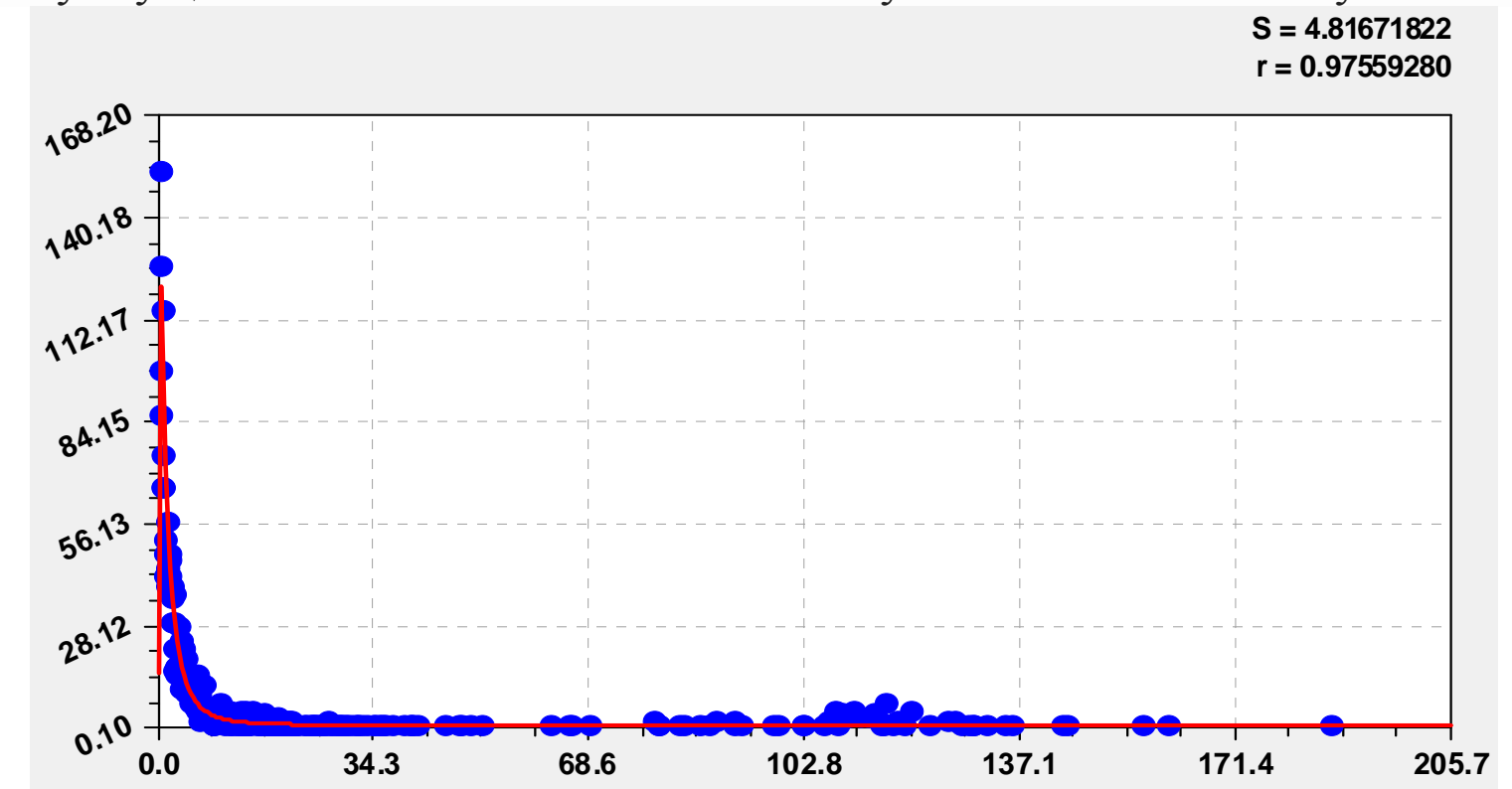

Рис. 1. Тренд изменения численности лесных $3 У$ от площади ЗУ

( $S$ - дисперсия; $r$ - коэффициент корреляции)

Коэффициент корреляции детерминированной модели типа (1) равен 0,9756. По данным таблицы 2 это значение соответствует уровню адекватности «сверхсильная факторная связь».

На рисунке 2 приведены остатки от формулы (1).

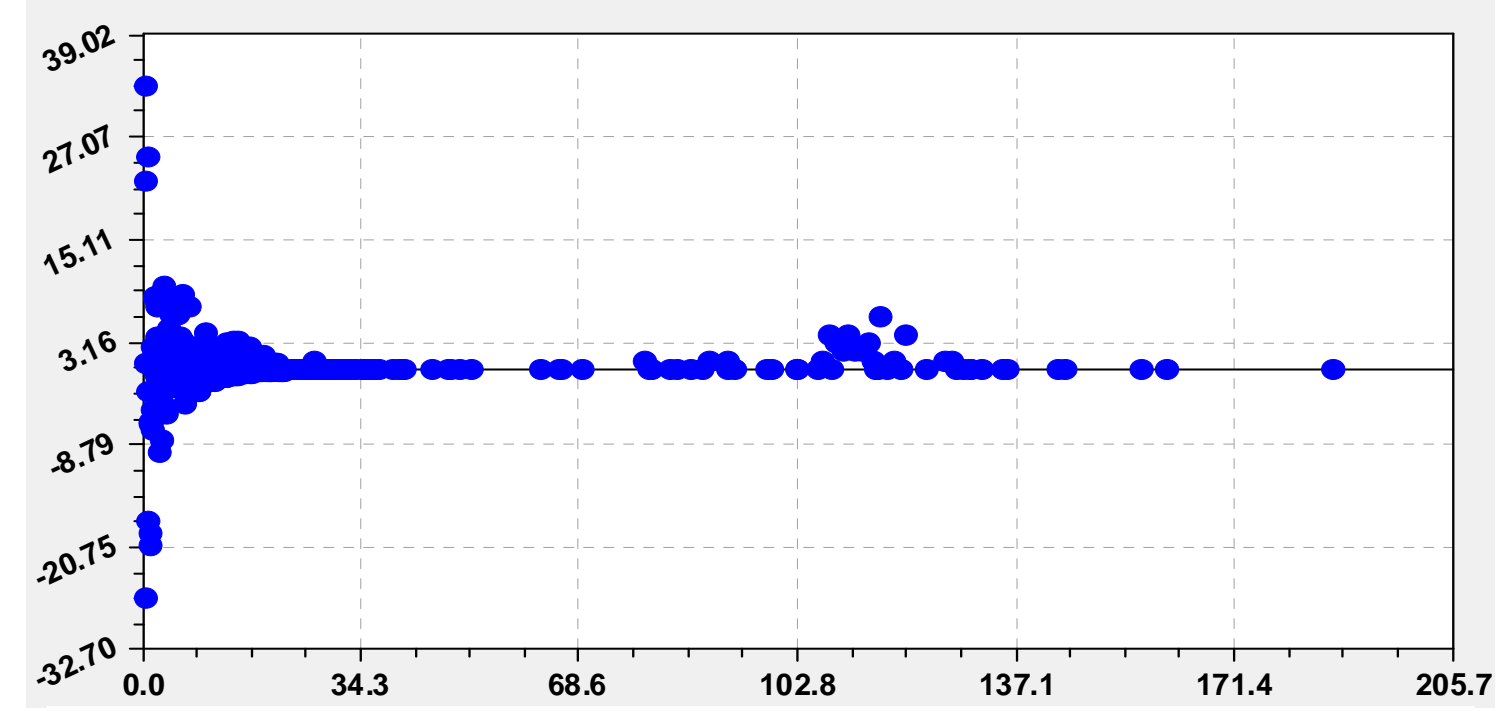

Рис. 2. Остатки после тренда изменения численности лесных $3 У$ от площади ЗУ

В некоторых точках наблюдаются высокие погрешности модели (3), особенно по площади от нуля до 10 га. Малые интервалы площади, как известно, появляются из измельчения лесных выделов делянками под рубки деревьев. Поэтому здесь можно ожидать появления волнового возмущения количества лесных земельных участков. 
На рисунке 3 показан график волновой составляющей.

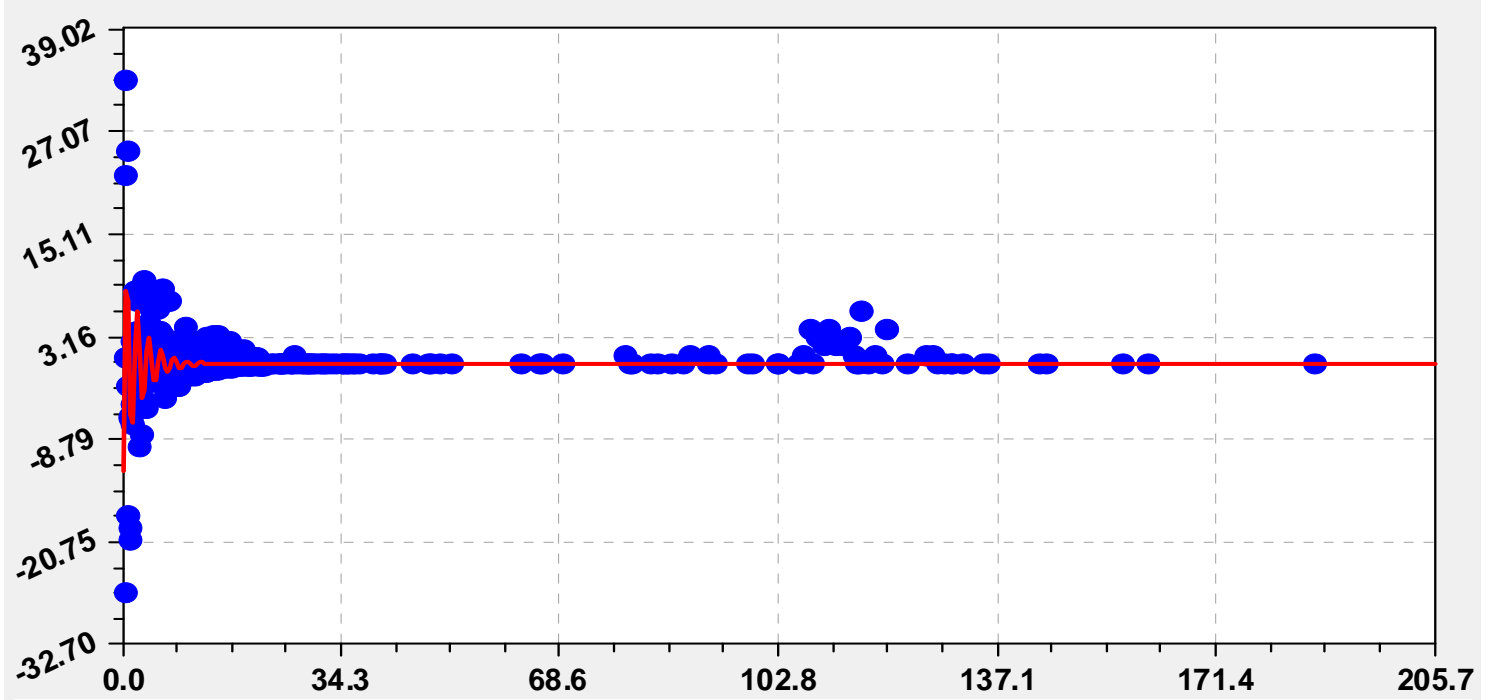

Рис. 3. Волновая составляющая после тренда численности лесных ЗУ от площади

Оп таблице 2 волновое уравнение получает слабоватый уровень адекватности. Поэтому его влияние на тренд мало значимое.

Общее уравнение (рис. 4) получает вид

$$
\begin{gathered}
N=1+8.31094 \cdot 10^{8} S^{2.37633} \exp \left(-16.24104 S^{0.18986}\right)- \\
-A \cos (\pi S / p+0.90729) \\
A=20.54267 \exp (-0.51558 S), p=-8.15391+8.92642 S^{0.0060973}
\end{gathered}
$$

По параметрам модели (4) получается, что при нулевой площади всего один участок получает значение площади в 20,54 га. При этом с увеличением площади полупериод колебания возрастает. В интервале площади от 0,1 до 187 га полупериод колебания изменяется от 1,06 до 0,65 га.

$r=0.98068962$

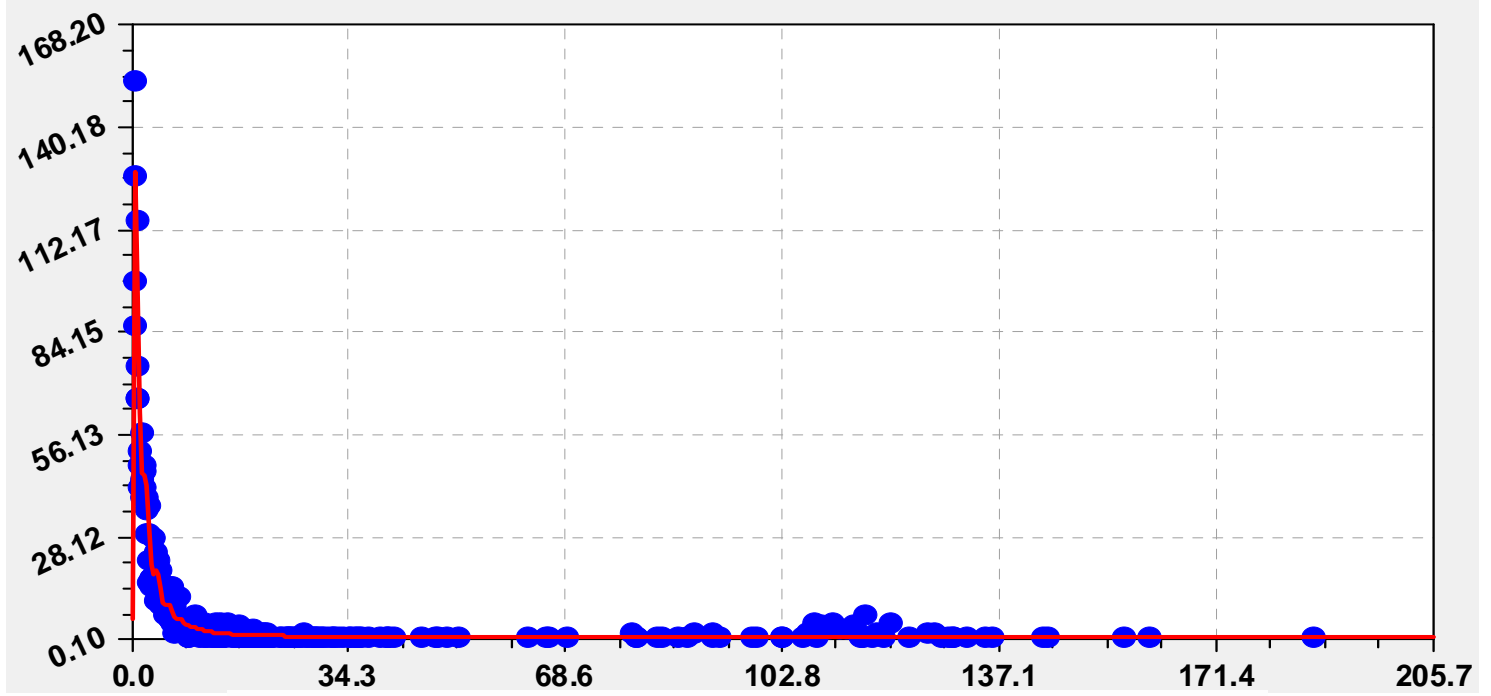

Рис. 4. Тренд и волновая составляющая общей модели (4) изменения численности лесных $3 У$ от площади 
Коэффициент корреляции возрос до 0,9807.

Ранговое распределение лесных земельных участков. В таблице 4 приведен фрагмент исходных данных для моделирования по результатам ранжирования площади лесных земельных участков Керебелякского лесничества национального парка «Марий Чодра».

Из данных таблицы 4 видно, что общее количество лесных земельных участков, включая покрытые (лесные выдела) и не покрытые лесом участки, равно 2807 шт.

Ранжирование по вектору предпорядка предпочтительности «лучше $\rightarrow$ хуже» было выполнено из экологического условия «чем больше площадь, тем лучше». Это же направление действительно и при хозяйственном освоении лесных массивов, хотя рубки малыми делянками сильно нарушают структурное распределение лесных выделов. Они с годами становятся мельче.

Поэтому нужно искать способы, не нарушающие распределение площади выделов. А это возможно только при запрещении технологий сп-

Таблица 4. Влияние ранга на площадь лесных земельных участков

\begin{tabular}{|c|c|c|}
\hline $\begin{array}{c}\text { № } \\
\text { П/п }\end{array}$ & $\begin{array}{c}\text { Ранг } \\
R_{S}\end{array}$ & $\begin{array}{c}\text { Площадь } \\
S, \text { га }\end{array}$ \\
\hline 1 & 0 & 187 \\
\hline 2 & 1 & 161 \\
\hline 3 & 2 & 157 \\
\hline 4 & 3 & 145 \\
\hline 5 & 4 & 144 \\
\hline$\ldots$ & $\ldots$ & $\ldots$ \\
\hline 2802 & 282 & 0.1 \\
\hline 2803 & 282 & 0.1 \\
\hline 2804 & 282 & 0.1 \\
\hline 2806 & 282 & 0.1 \\
\hline 2807 & 282 & 0.1 \\
\hline
\end{tabular}
лошных рубок в пользу способов выборочной рубки лесных деревьев.

По модели (1), при $a_{2}=0$, получен (рис. 5) двухчленный тренд

$$
\begin{gathered}
S=147.33528 \exp \left(-0.0078694 R_{S}{ }^{1.12782}\right)- \\
-2.95232 \cdot 10^{-17} R_{S}{ }^{20.25037} \exp \left(-6.45762 R_{S}{ }^{0.45525}\right) .
\end{gathered}
$$

$S=1.55041086$ $\mathrm{r}=0.99699611$

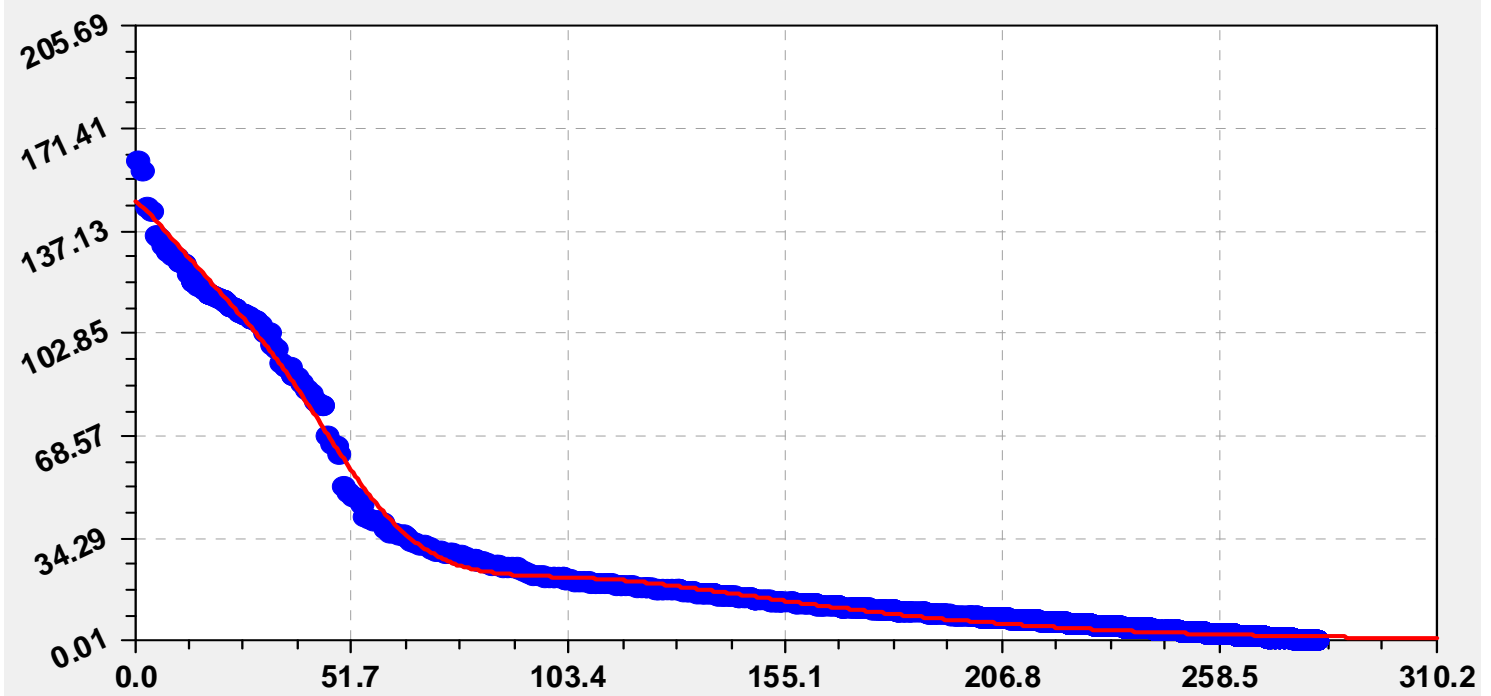

Рис. 5. Двухчленный тренд рангового распределения площади лесных ЗУ

Коэффициент корреляции формулы (5) равен 0,9970. По таблице 2 это относит модель (5) к уровню адекватности «чрезвычайно сильная». 
Для производственных расчетов формула (5) достаточна. Однако для выявления волновых изменений нужно знать и вейвлет-сигналы. Их осмысление позволит понять поведение лесных ЗУ в рассматриваемом лесничестве и углубить лесную науку.

Первая волна колебательного возмущения показана на рисунке 6.

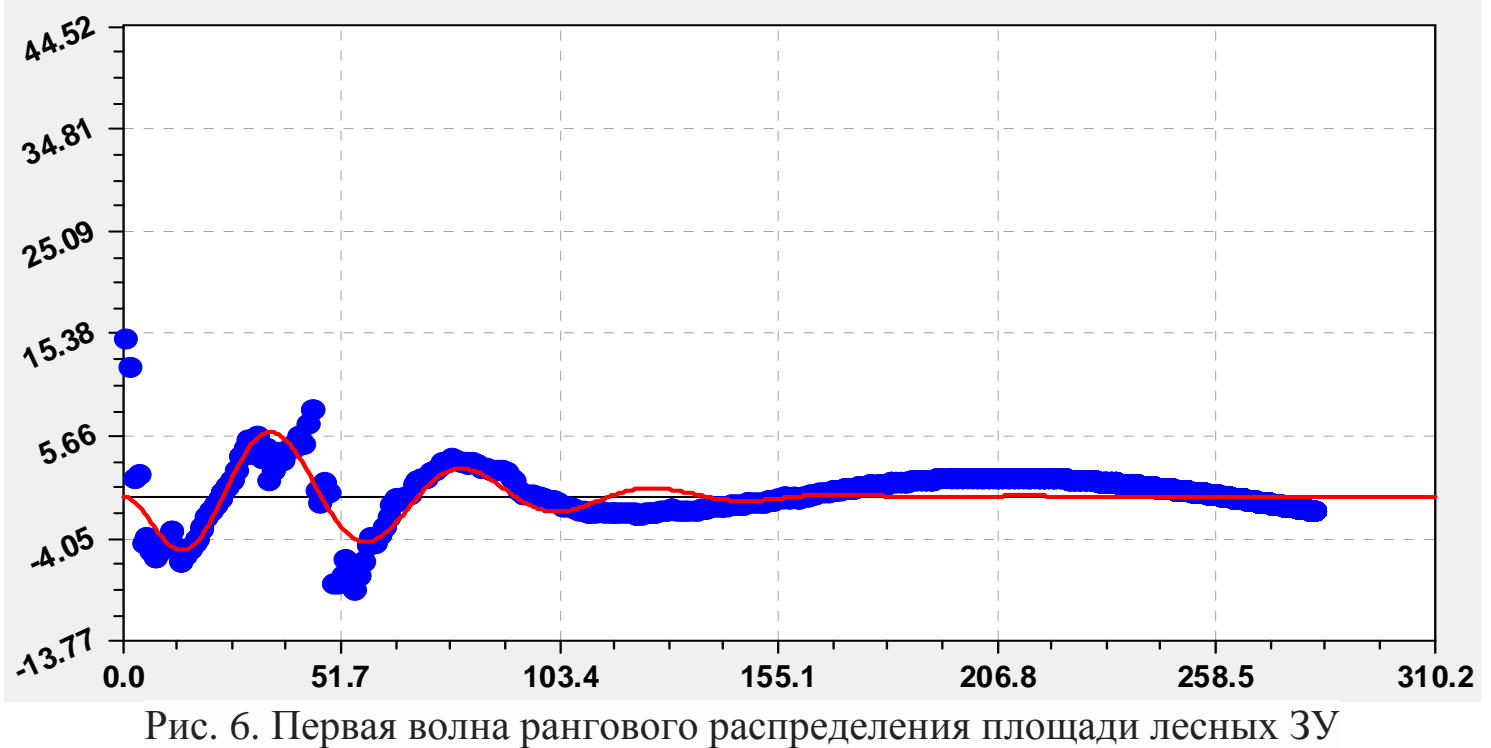

Параметры моделей всех вейвлет-сигналов приведены в таблице 5. Вторая волна колебательного возмущения показана на рисунке 7. $S=0.44617113$ $r=0.92072145$

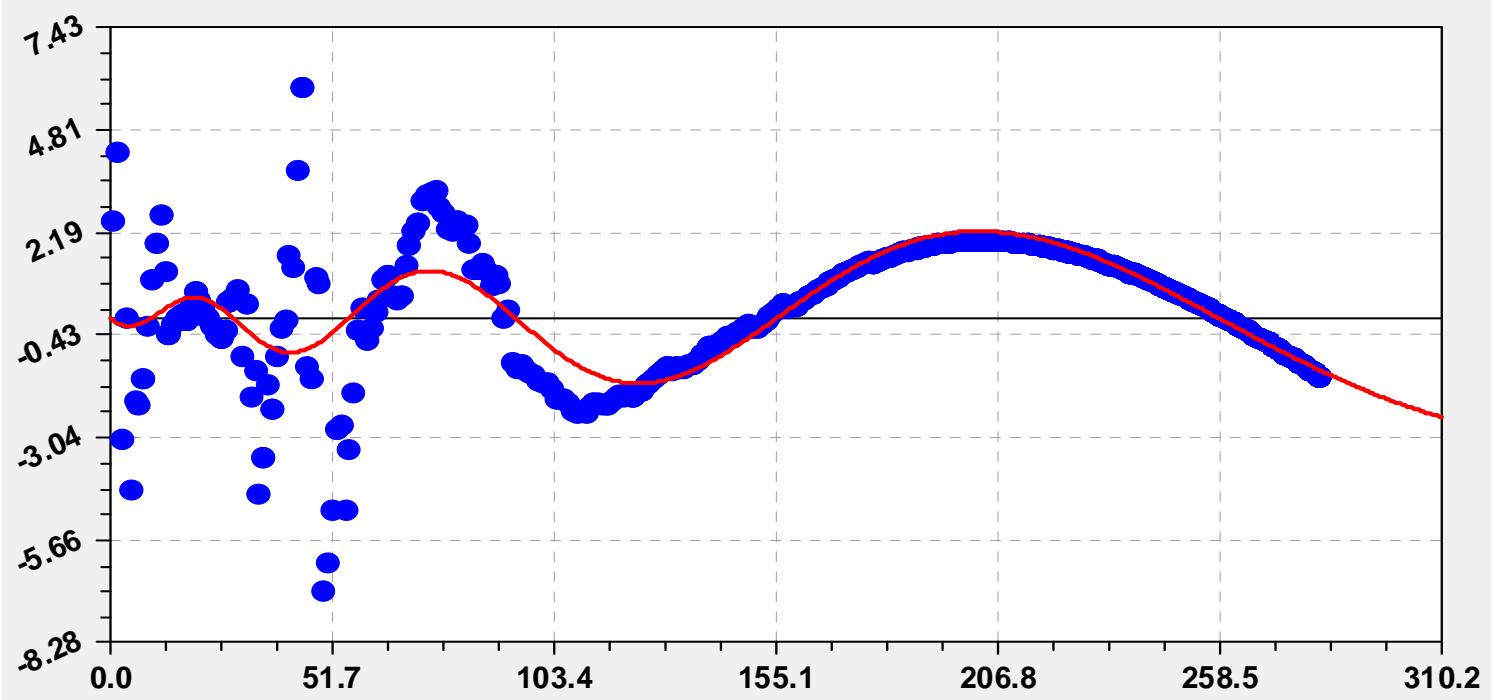

Рис. 7. Вторая волна рангового распределения площади лесных ЗУ

Четырехчленная модель (индекс ранга опущен) дается (рис. 8) так:

$$
S=S_{1}+S_{2}+S_{3}+S_{4},
$$

$S_{1}=187.45647 \exp \left(-0.015766 R^{1.02442}\right)$, 


$$
\begin{aligned}
& S_{2}=-2.86717 \cdot 10^{-15} R^{19.19598} \exp \left(-6.36778 R^{0.45949}\right), \\
& S_{3}=A_{1} \cos \left(\pi R / p_{1}+2.13633\right) \\
& A_{1}=49.69459 R^{0.31415} \exp \left(-0.19098 R^{0.75487}\right), \\
& p_{1}=54.47474-0.46131 R^{1.02025}, S_{4}=A_{2} \cos \left(\pi R / p_{2}-3.17357\right), \\
& A_{2}=0.053377 R^{0.78235}, p_{2}=10.08538+0.18957 R^{0.95059}
\end{aligned}
$$

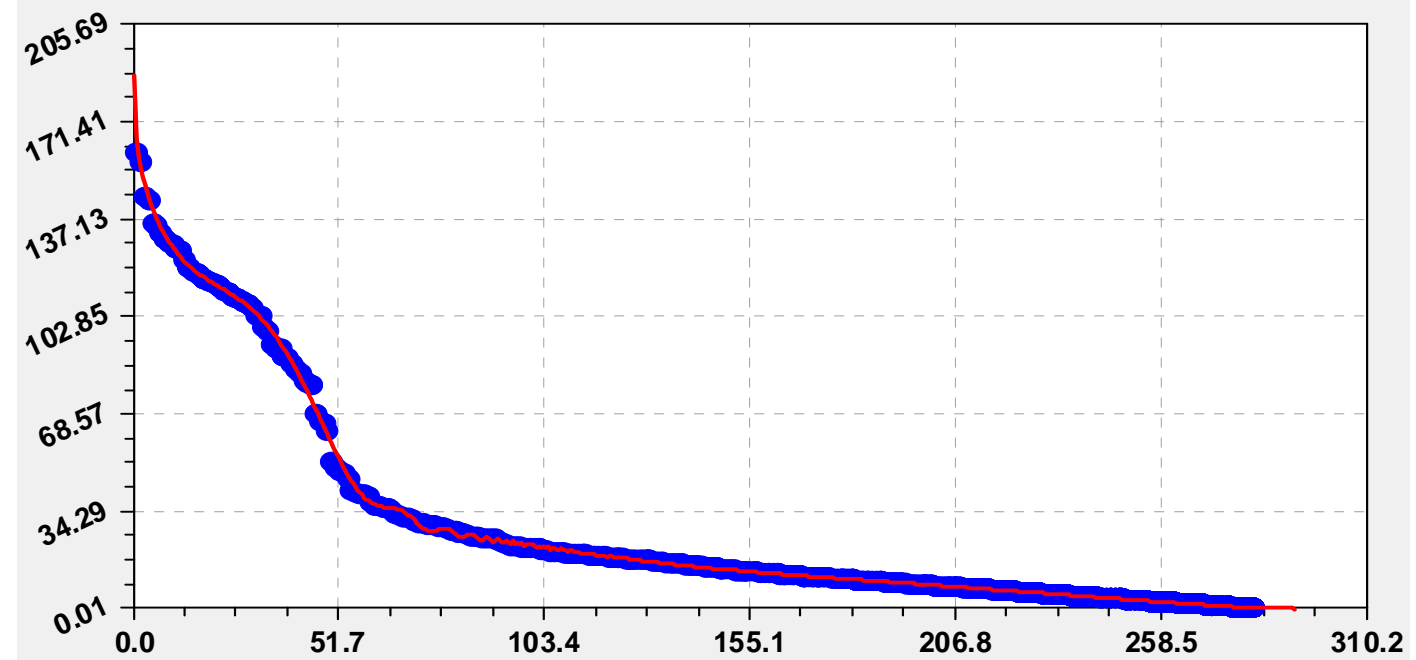

Рис. 8. Четырехчленная модель (6) рангового распределения площади лесных $3 У$

Коэффициент корреляции 0,9998 по таблице 2 относит модель (6) к уровню адекватности «почти однозначная» факторная связь.

Однако далее были получены (рис. 9 - 16) дополнительные вейвлеты, которые нужно будет эвристически идентифицировать как сигналы.

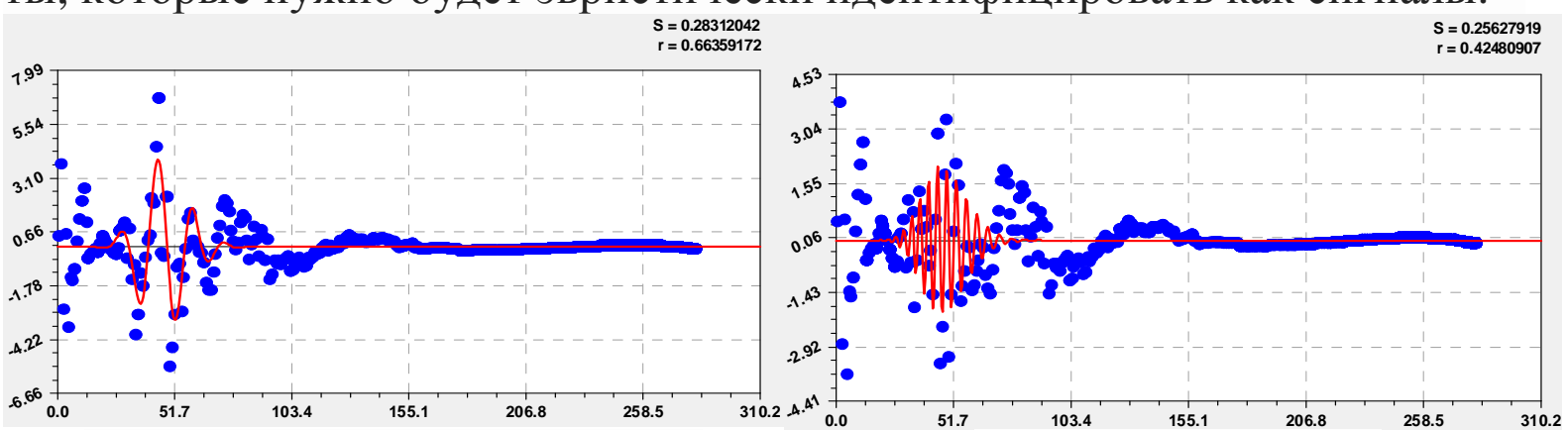

Пятая составляющая по модели (2)

Шестая составляющая

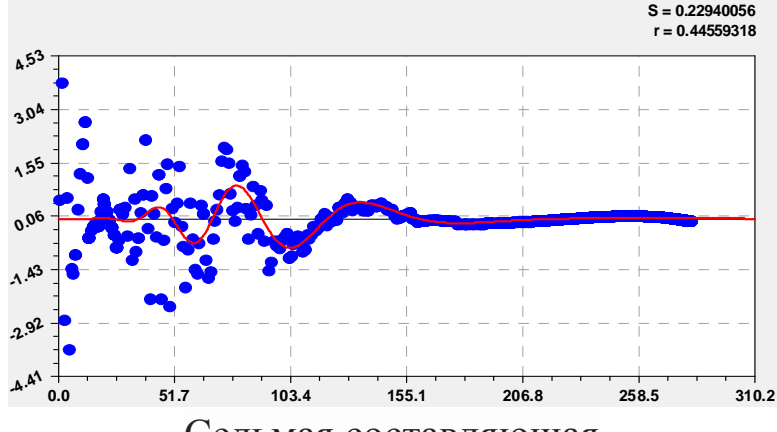

Седьмая составляющая

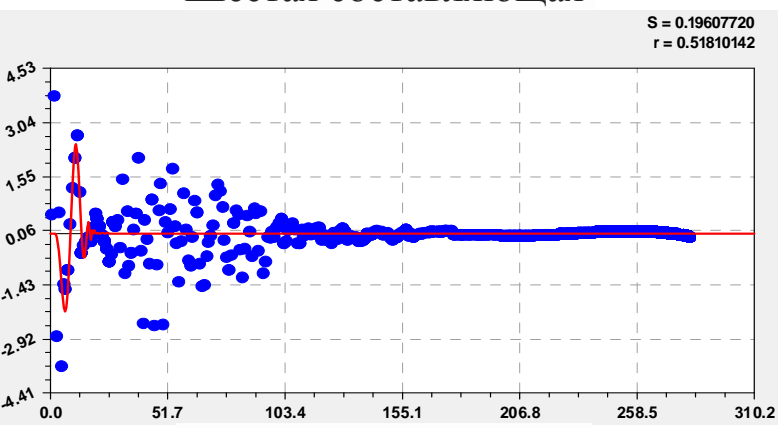

Восьмая составляющая

Рис. 9. Дополнительные вейвлеты рангового распределения площади лесных ЗУ 

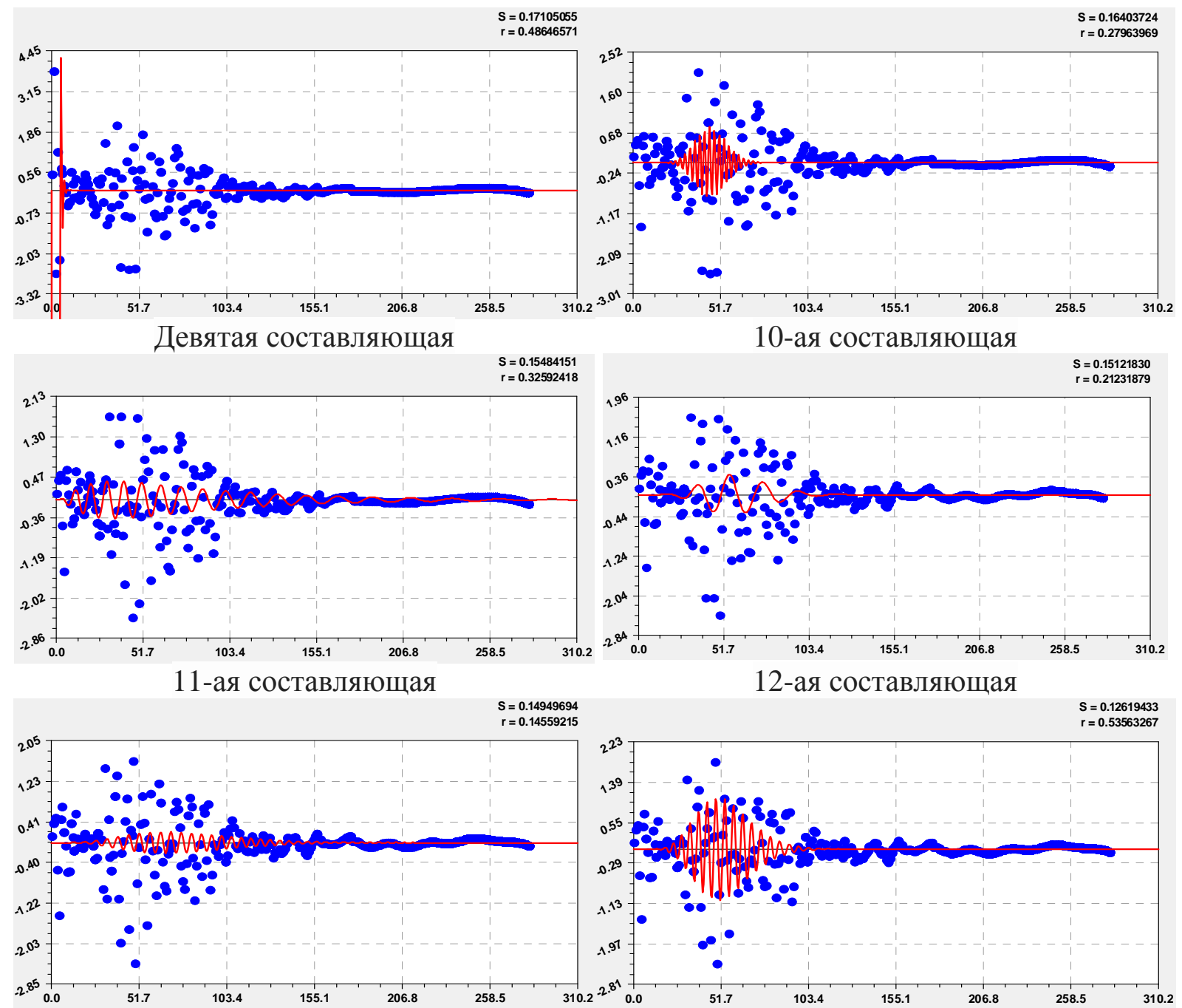

13-ая составляющая
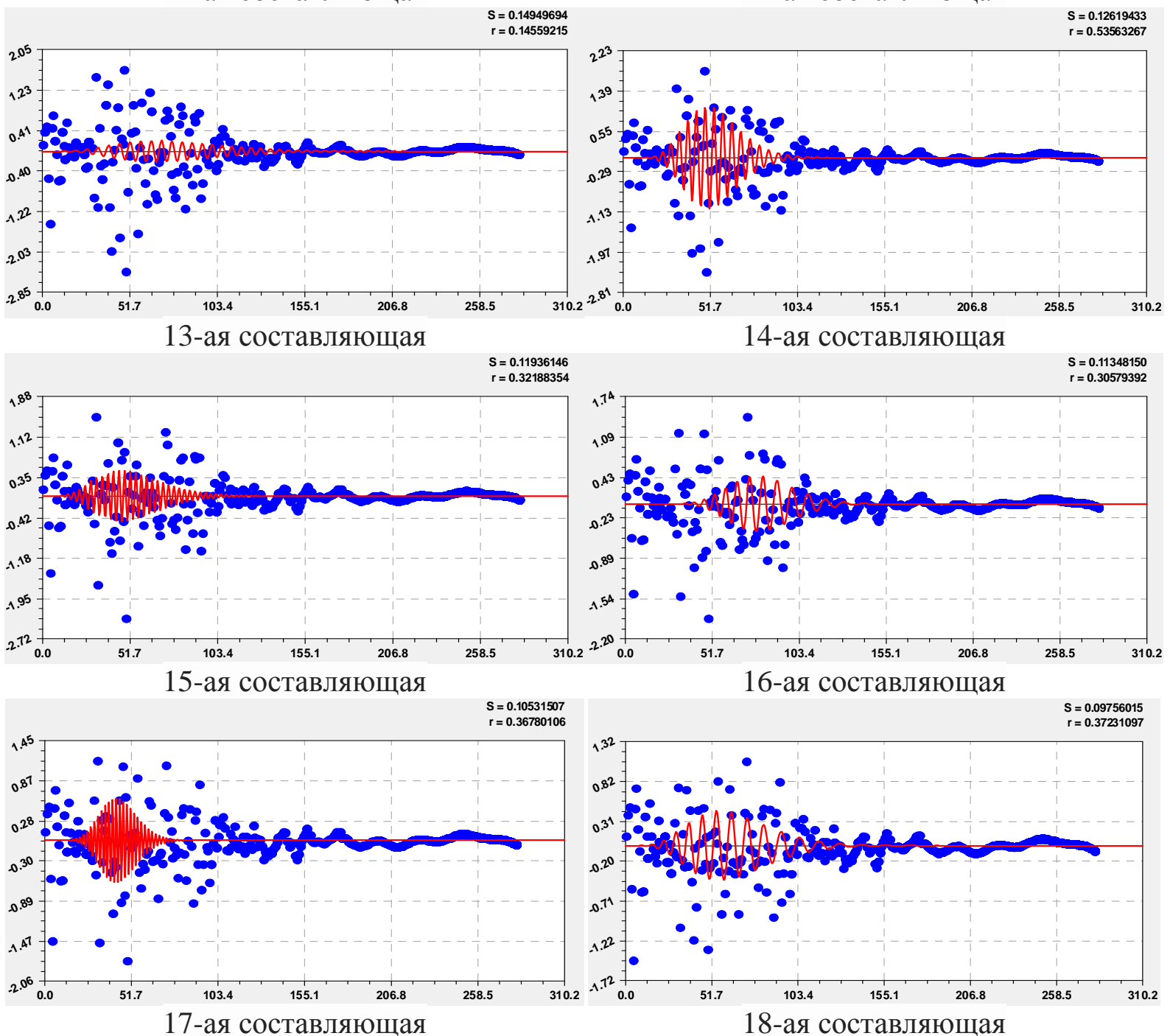

Рис. 10. Дополнительные вейвлеты рангового распределения площади лесных 3У 

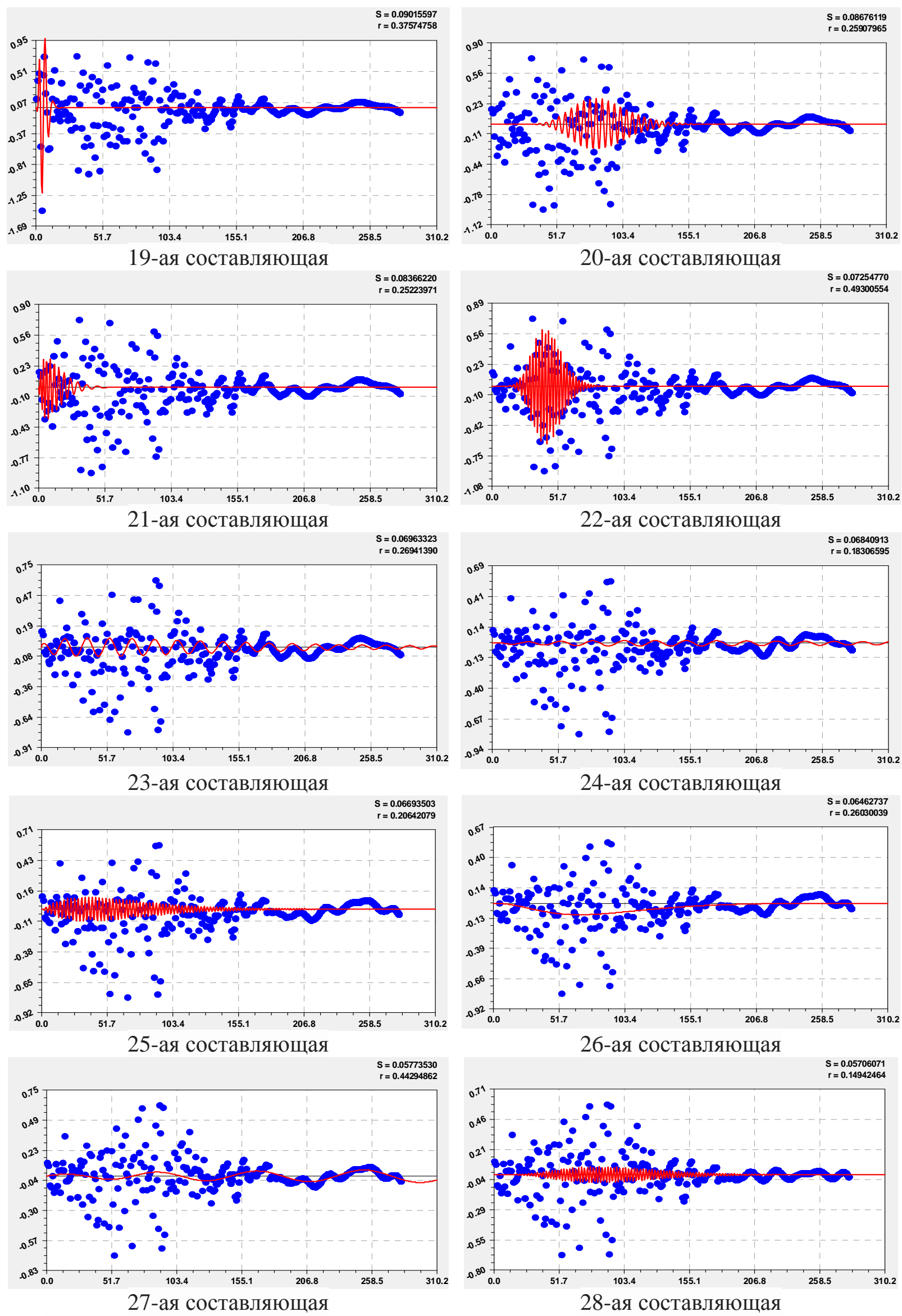

Рис. 11. Дополнительные вейвлеты рангового распределения площади лесных ЗУ 

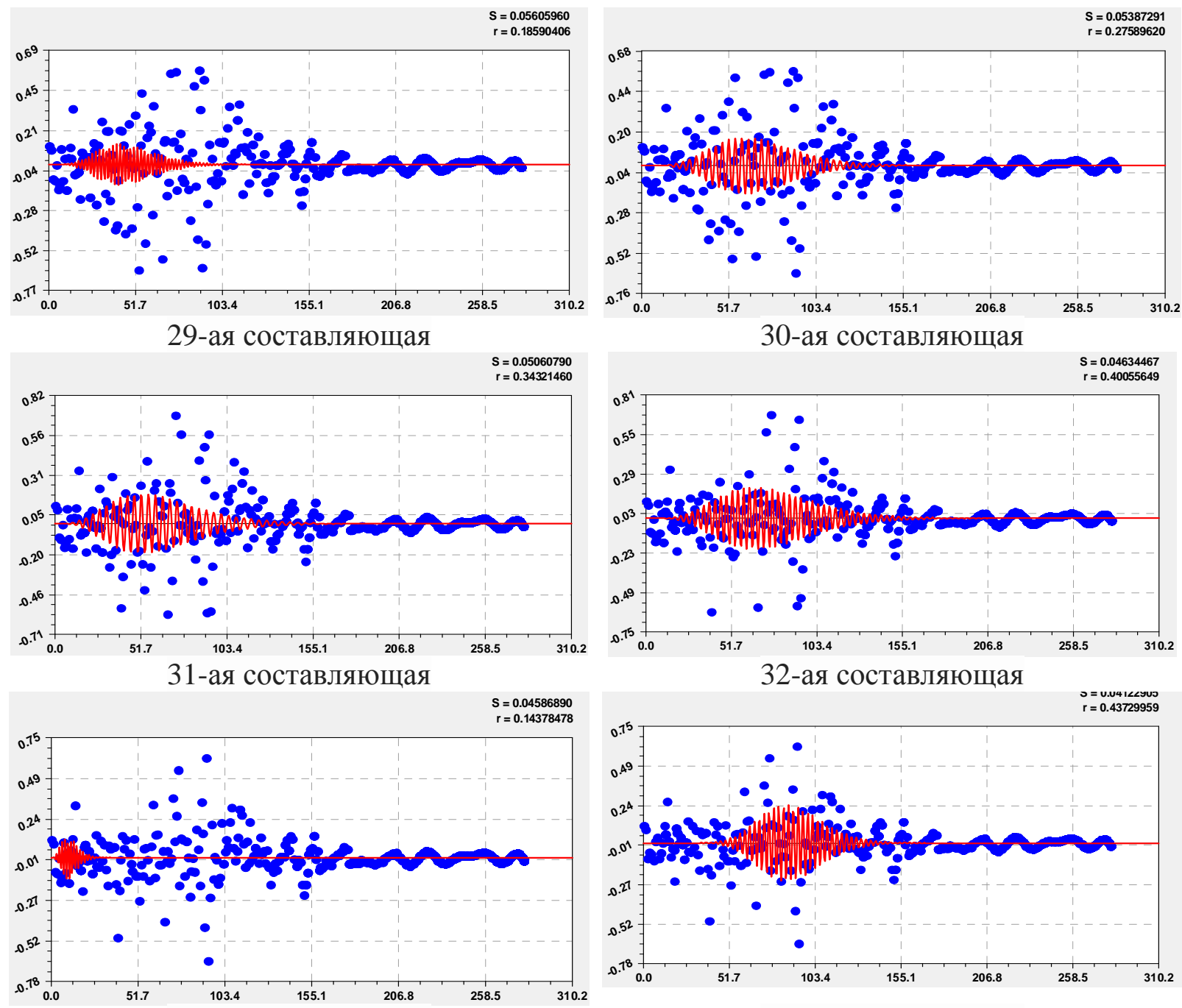

33-ая составляющая

34-ая составляющая
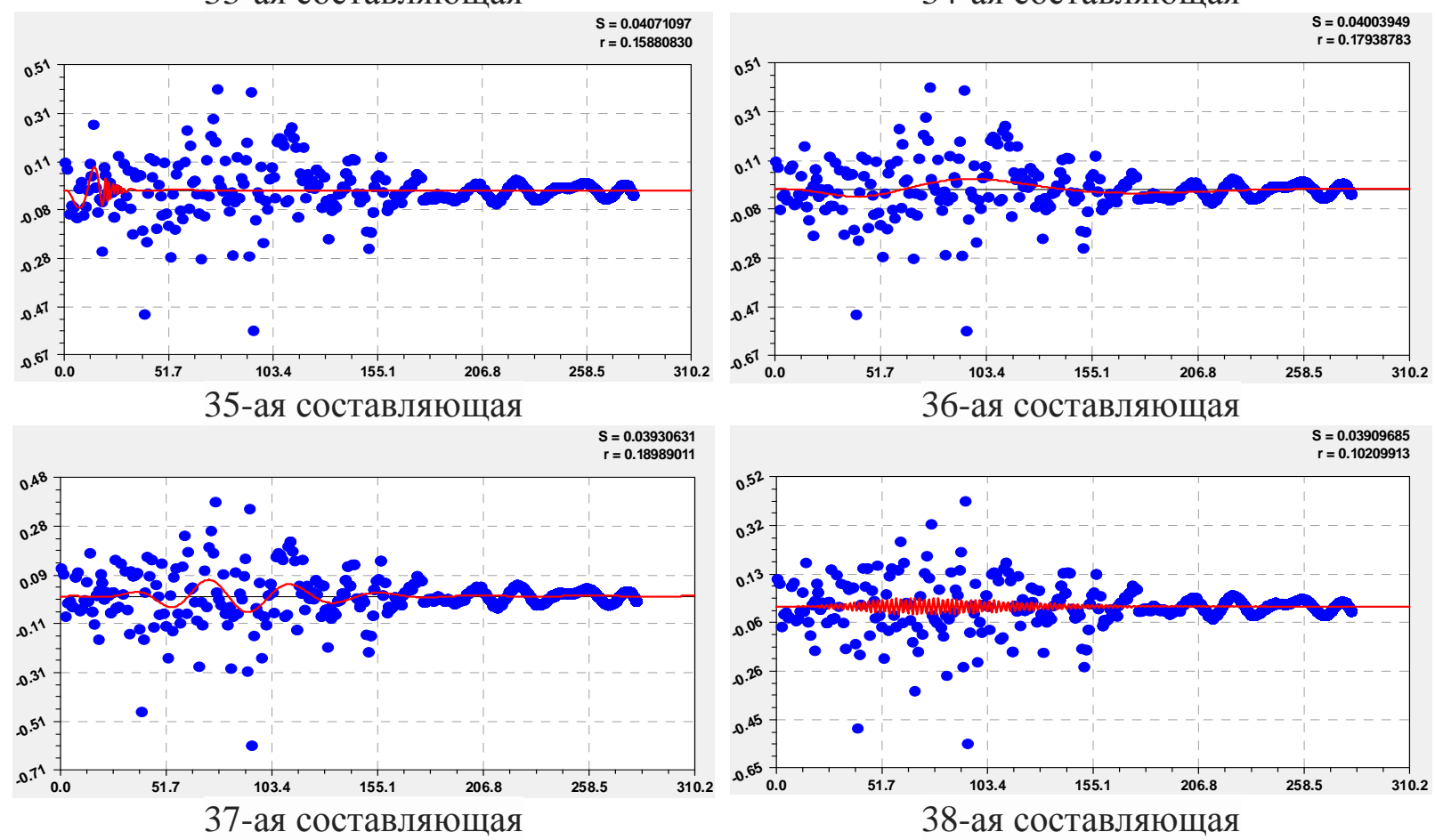

Рис. 12. Дополнительные вейвлеты рангового распределения площади лесных ЗУ 

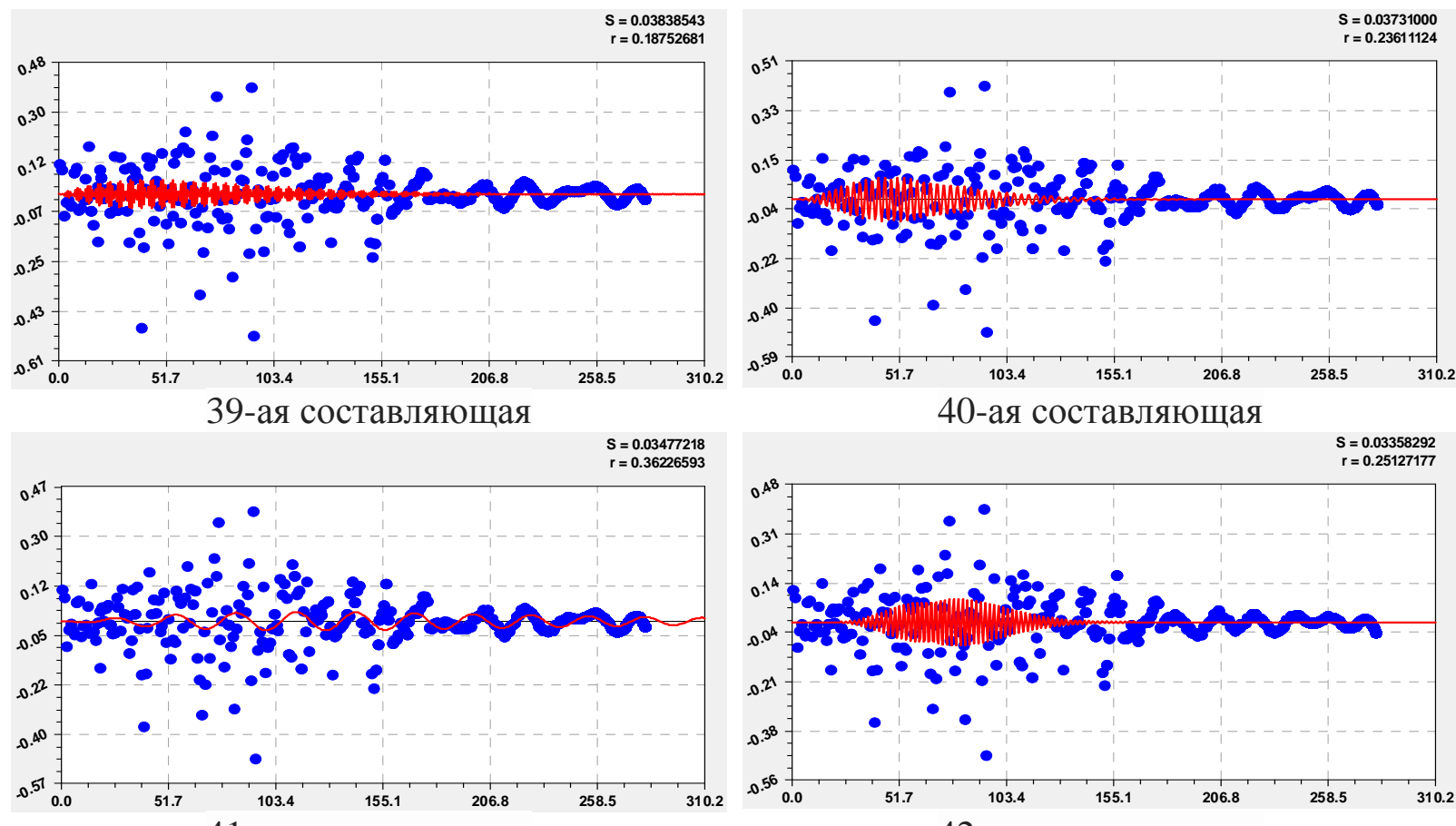

41-ая составляющая

42-ая составляющая

$S=0.03022377$
$r=0.43288765$

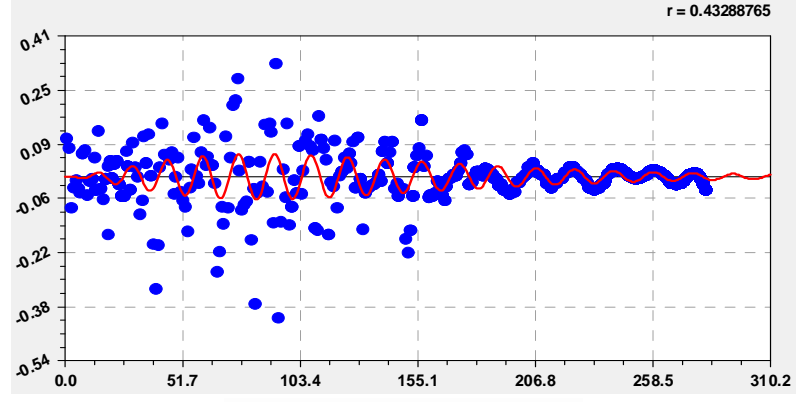

43-ая составляющая

$\mathrm{S}=0.02869528$

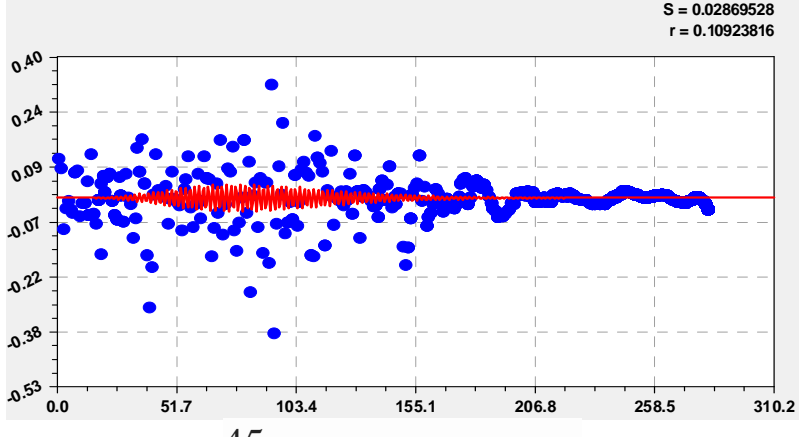

45-ая составляющая

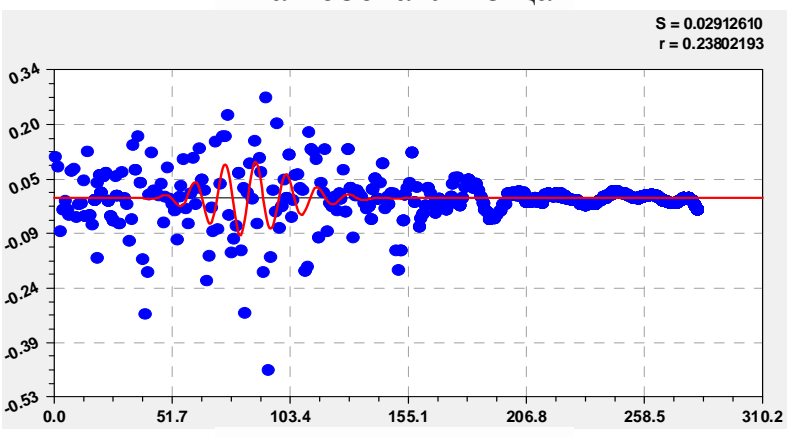

44-ая составляющая

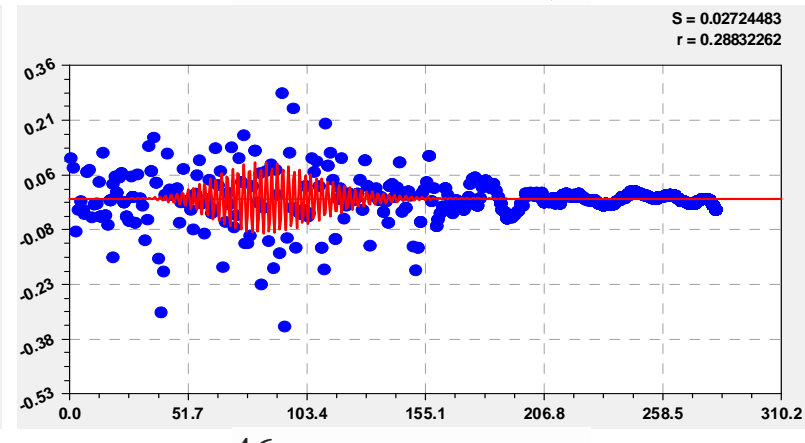

46-ая составляющая

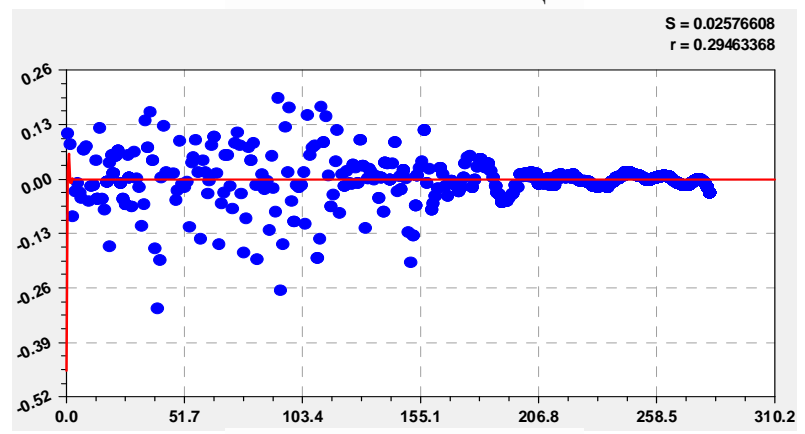

47-ая составляющая

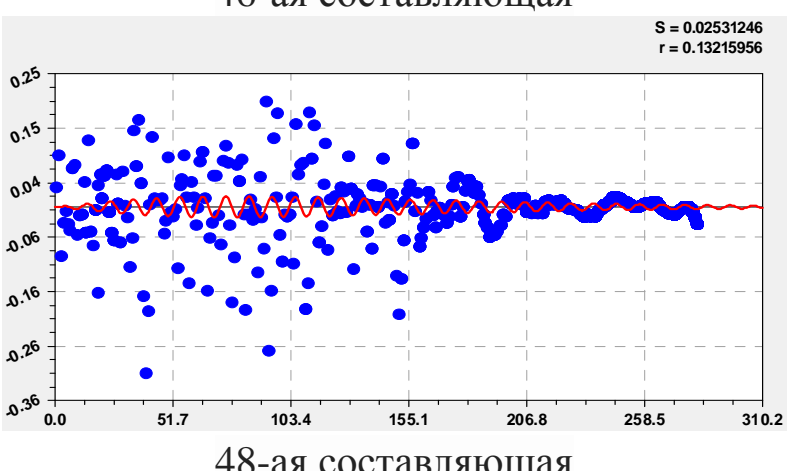

Рис. 13. Дополнительные вейвлеты рангового распределения площади лесных 3У 

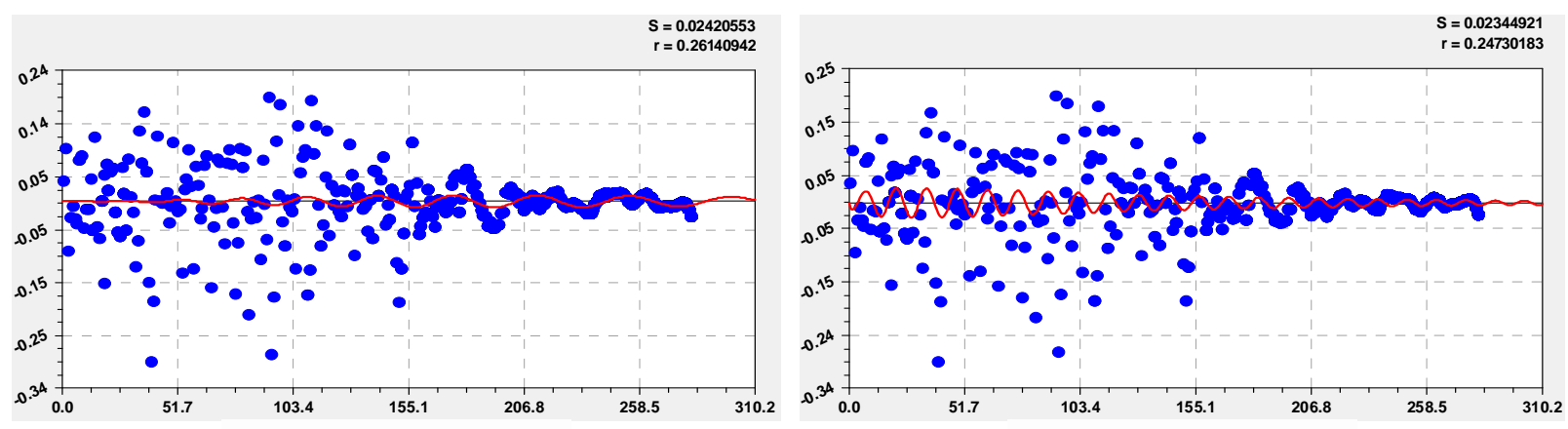

49-ая составляющая

50 -ая составляющая
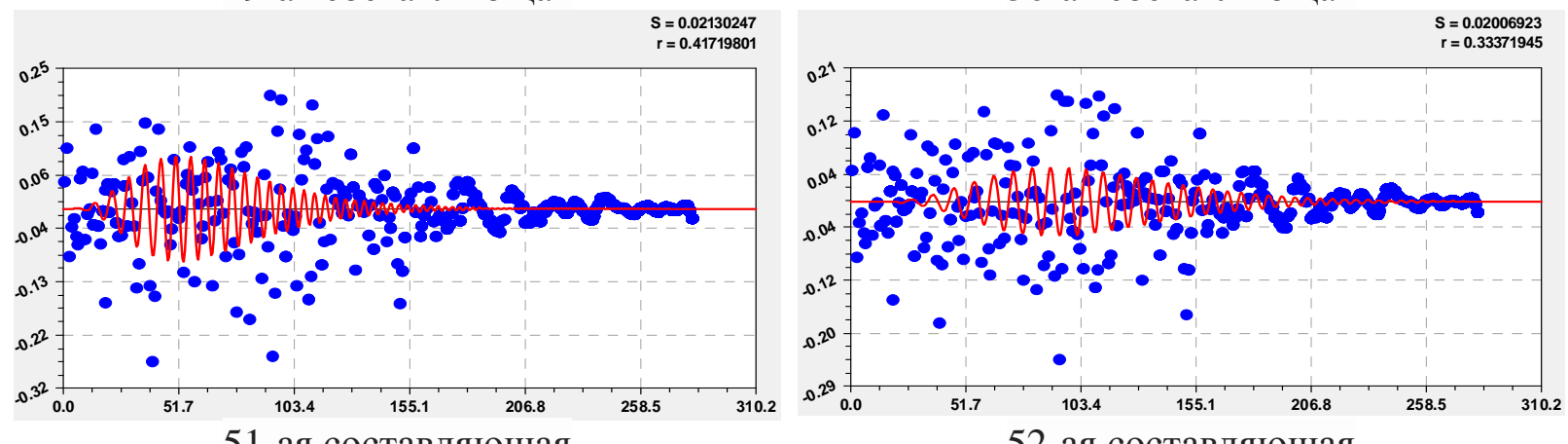

51-ая составляющая

52-ая составляющая

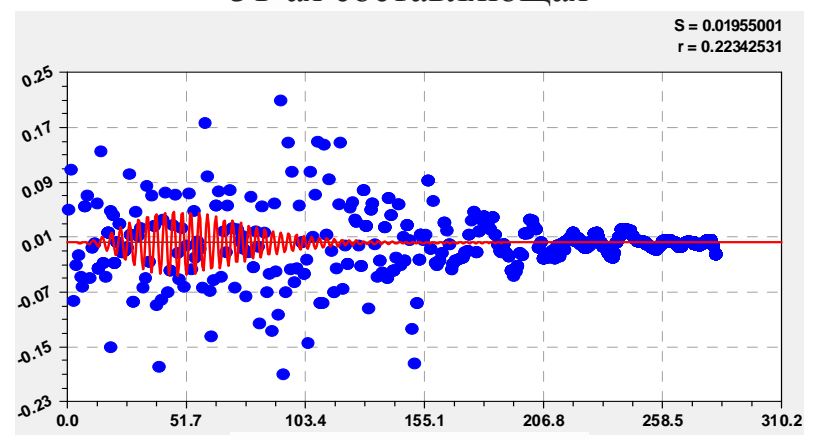

53-ая составляющая
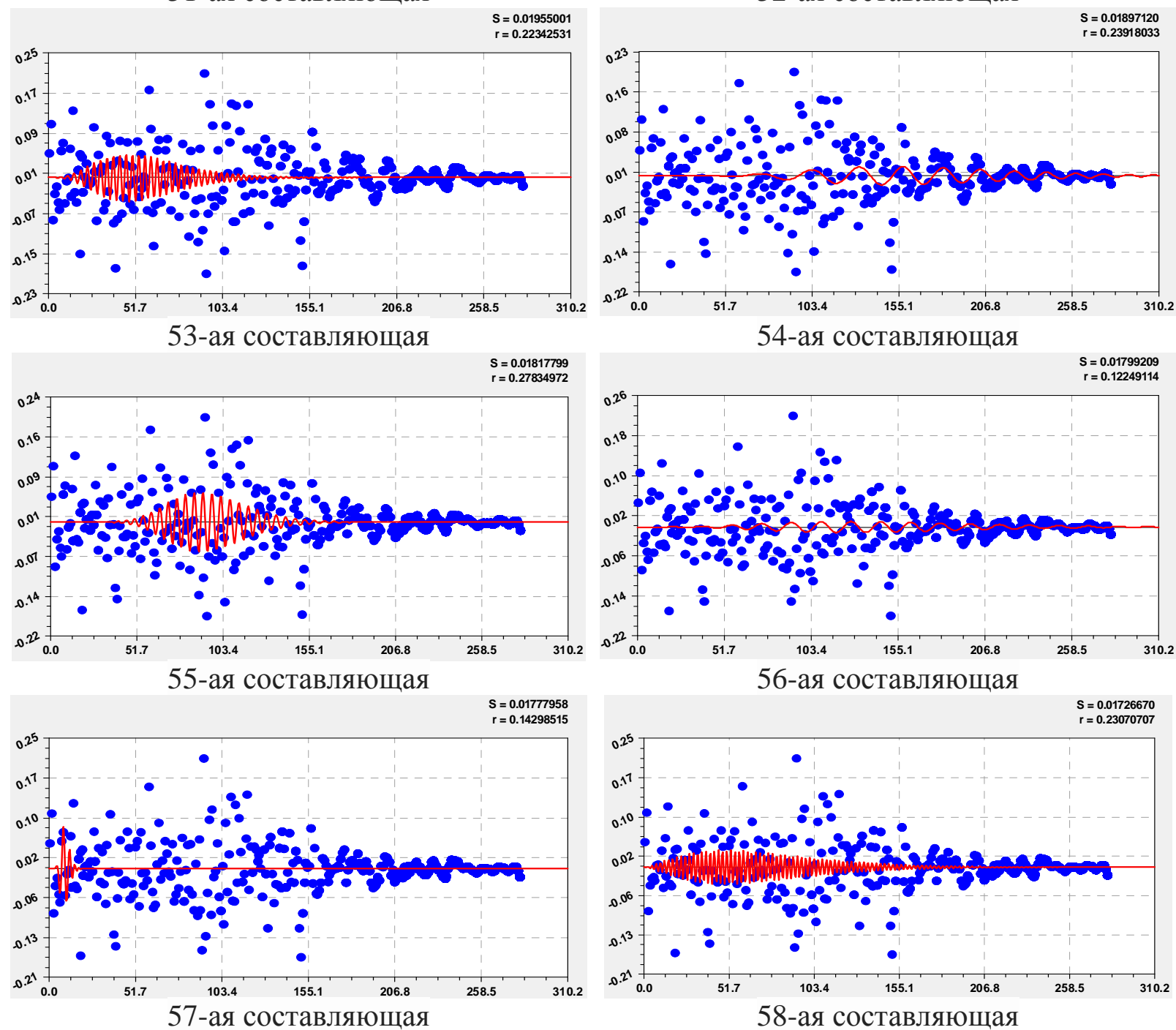

Рис. 14. Дополнительные вейвлеты рангового распределения площади лесных ЗУ 

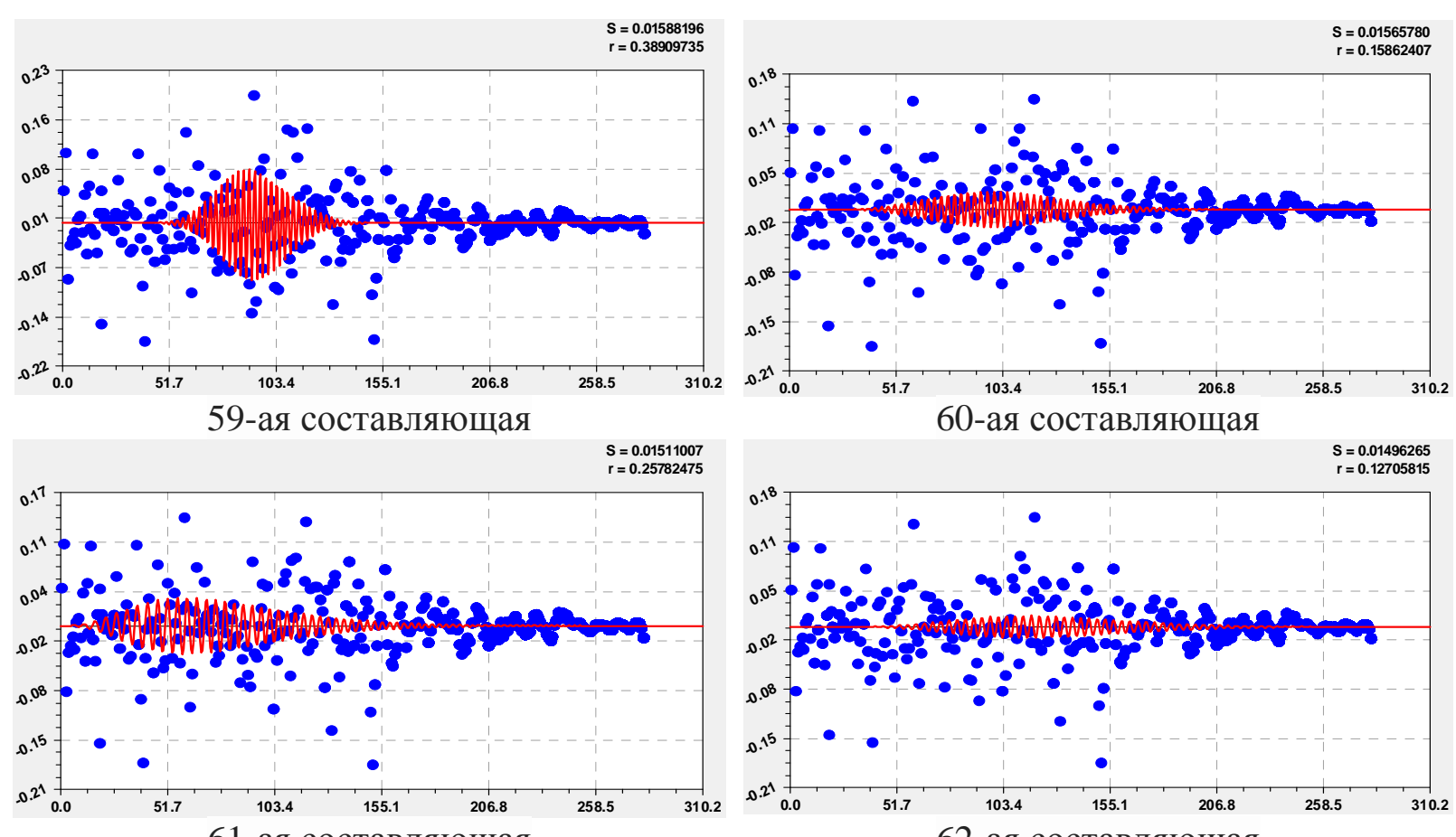

61-ая составляющая

62-ая составляющая

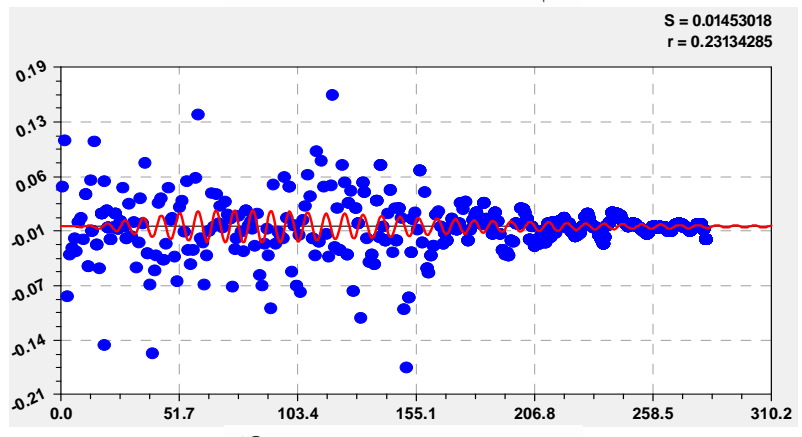

63-ая составляющая
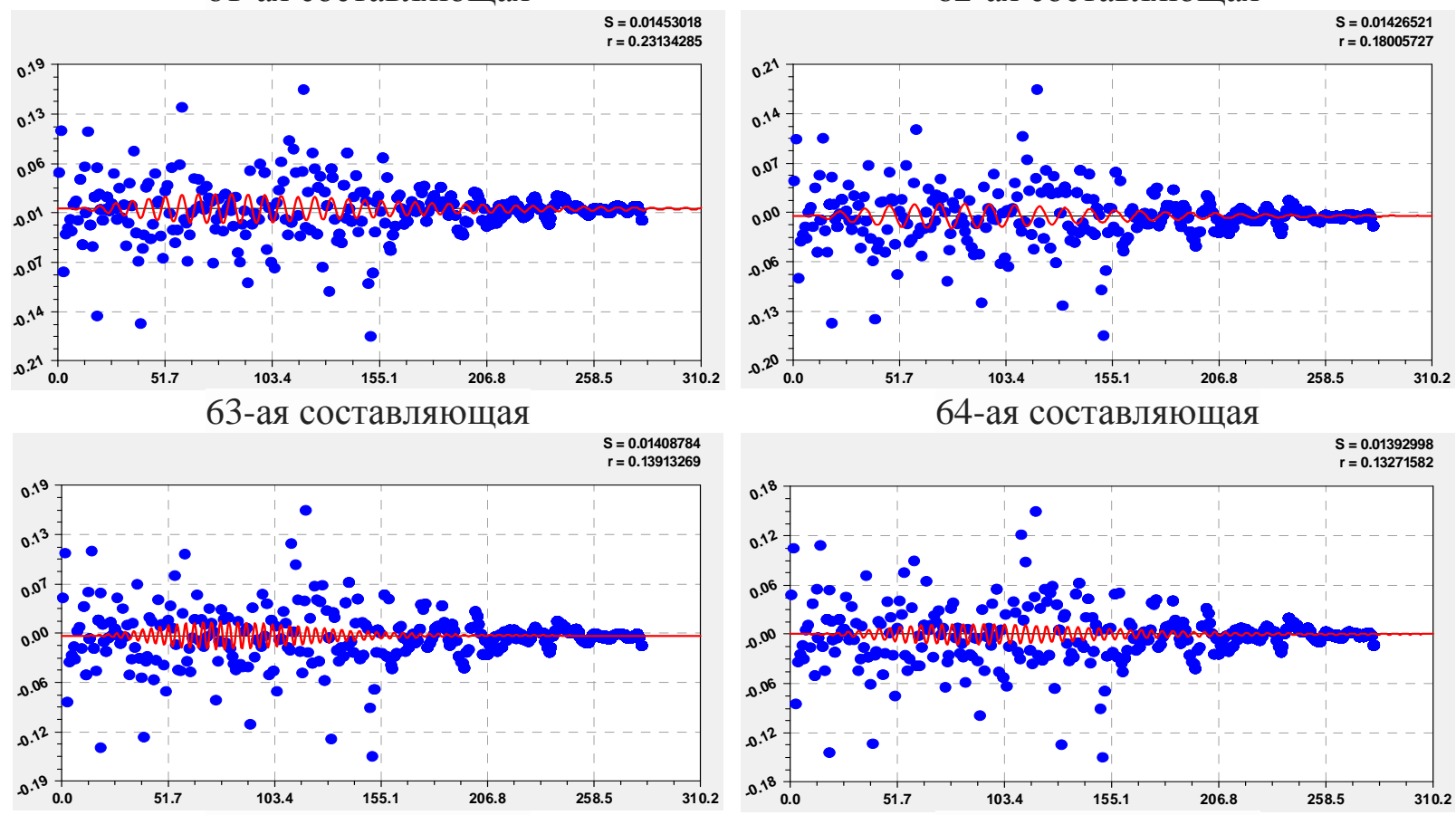

65-ая составляющая

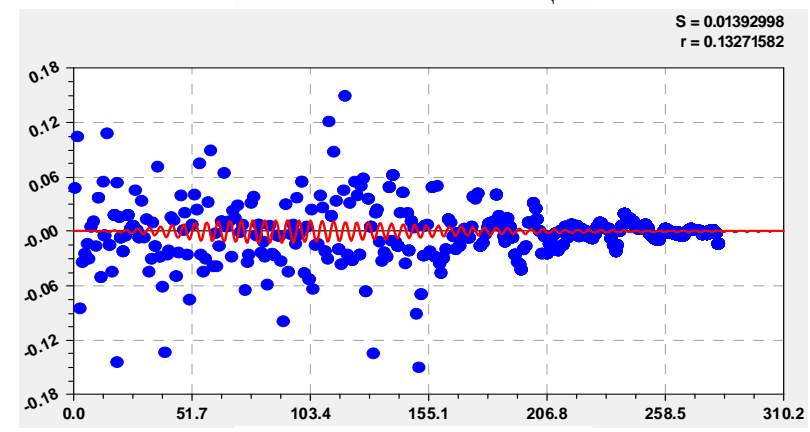

66-ая составляющая

$S=0.01368016$
$r=0.17808565$
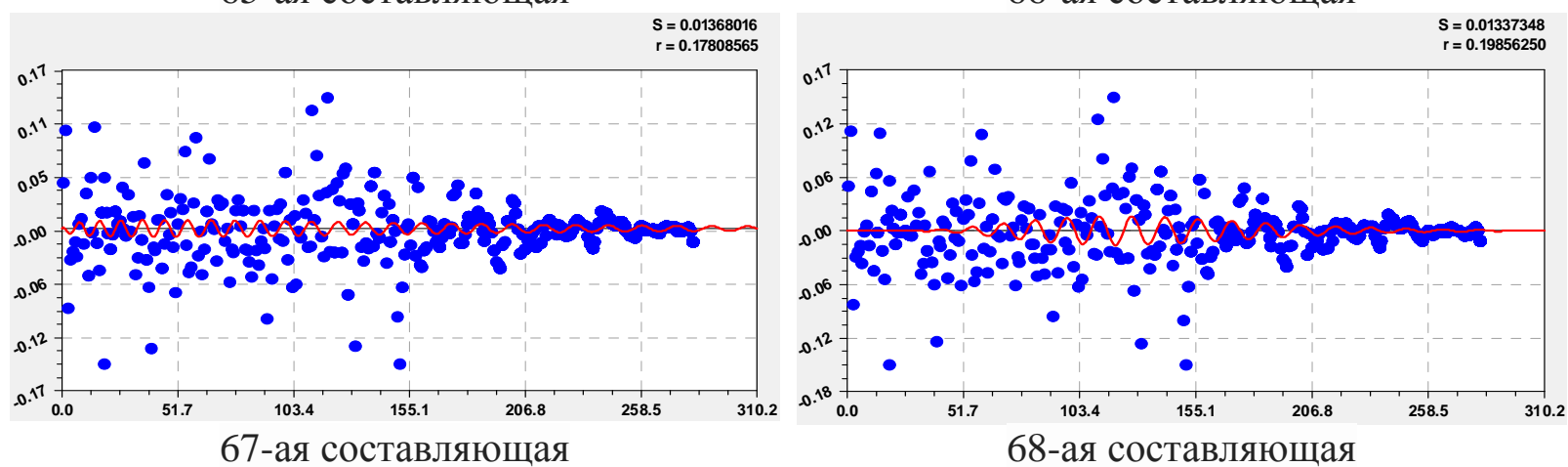

Рис. 15. Дополнительные вейвлеты рангового распределения площади лесных 3У 

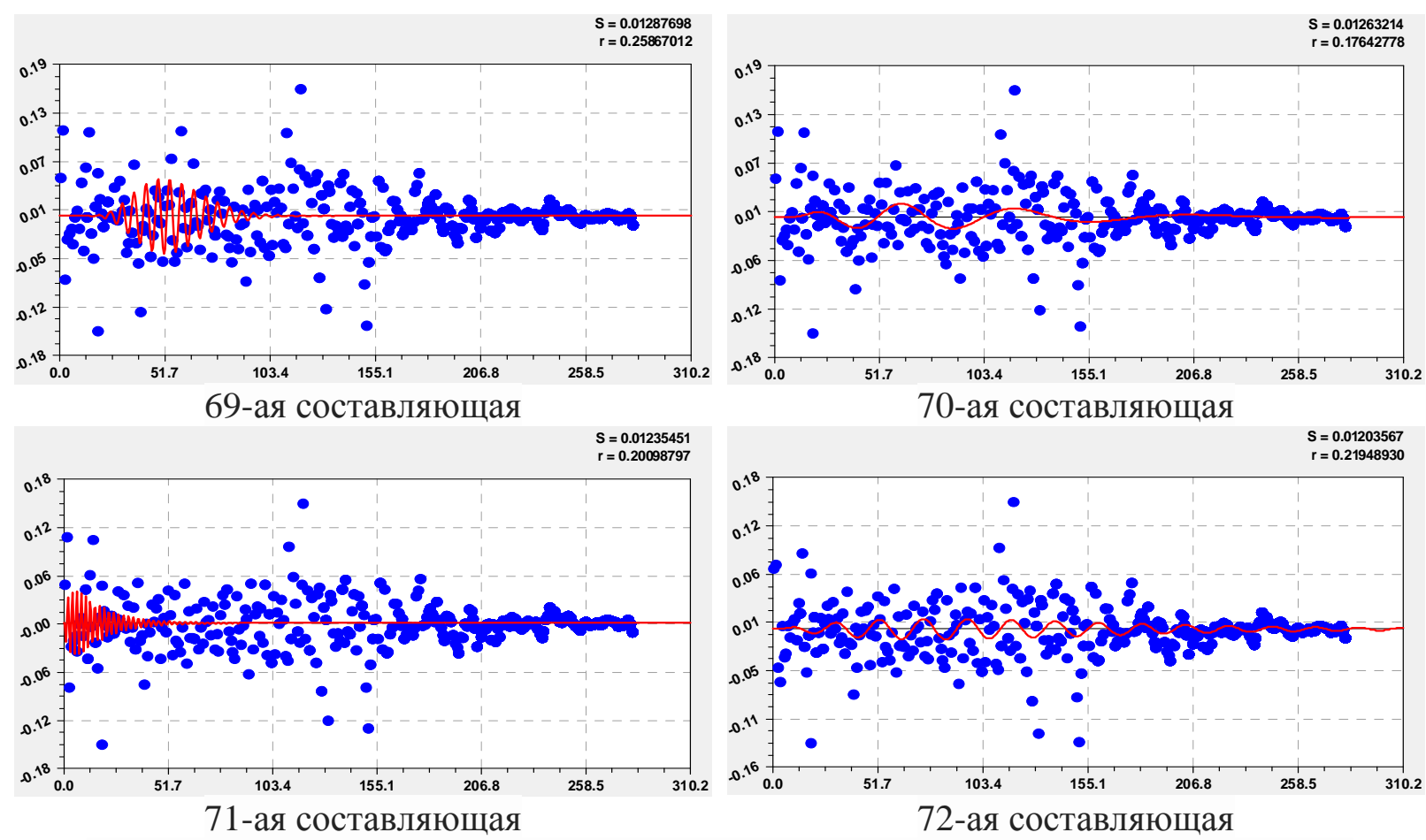

Рис. 16. Окончательные вейвлеты рангового распределения площади лесных ЗУ

На рисунке 17 приведены точечный график остатков (абсолютной погрешности) после 72-ой составляющей волновой модели (2). Теоретически можно продолжать процедуры вейвлет-анализа, однако коэффициент корреляции будет меньше 0,1. Поэтому практически полный вейвлетанализ завершен. Для доказательства этого нужна верификация.

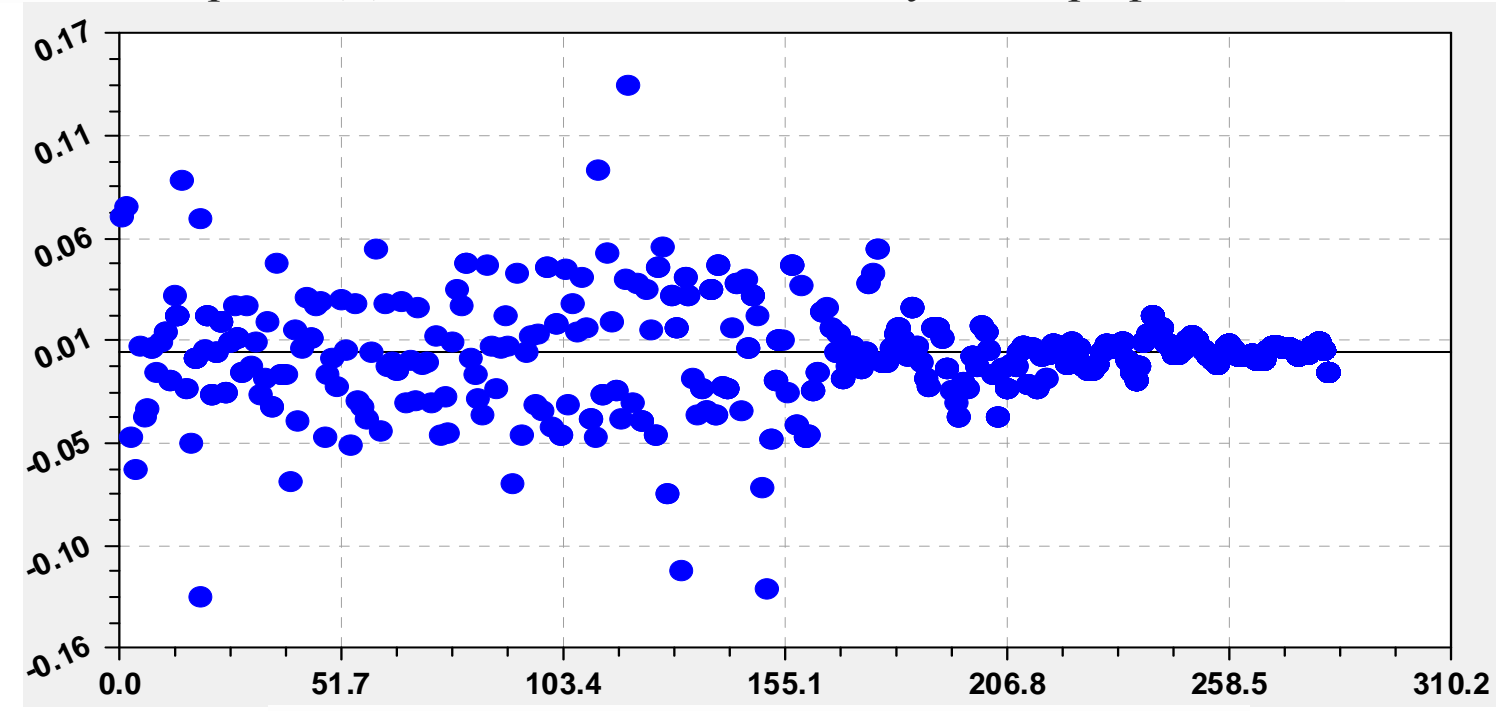

Рис. 17. Остатки после 72-ой составляющей модели (2)

Из точечного графика на рисунке 17 видно, что остатки получили малые значения. Дальнейшую идентификацию модели (2) можно продолжить, однако коэффициент корреляции будет меньше 0.1. факт получения большого количества составляющих указывает на то, что популяция лесных земельных участков Керебелякского лесничества имеет больше есте 
ственную природу, и она менее всего испорчена антропогенным влиянием. Как будет показано в следующей статье, множество лесных выделов без земельных участков с пустыми от произрастающих деревьев территориями получил более мощное антропогенное воздействие (прежде всего рубками деревьев) и поэтому не получило полного вейвлет анализа.

Параметры всех 72 членов общей модели (2) приведены в таблице 5.

Таблица 5. Параметры модели рангового распределения всех лесных земельных участков Керебеляксого лесничества НП «Марий Чодра»

\begin{tabular}{|c|c|c|c|c|c|c|c|c|c|}
\hline \multirow{3}{*}{$i$} & \multicolumn{8}{|c|}{ Асимметричный вейвлет $y_{i}=a_{1 i} x^{a_{2 i}} \exp \left(-a_{3 i} x^{a_{4 i}}\right) \cos \left(\pi x /\left(a_{5 i}+a_{6 i} x^{a_{7 i}}\right)-a_{8 i}\right)$} & \multirow{3}{*}{$\begin{array}{c}\text { КоэФ. } \\
\text { корр. } \\
r\end{array}$} \\
\hline & \multicolumn{4}{|c|}{ Амплитуда (половина) колебания } & \multicolumn{3}{|c|}{ Полупериод колебания } & \multirow{2}{*}{$\begin{array}{c}\text { Сдвиг } \\
a_{8 i} \\
\end{array}$} & \\
\hline & $a_{1 i}$ & $a_{2 i}$ & $a_{3 i}$ & $a_{4 i}$ & $a_{5 i}$ & $a_{6 i}$ & $a_{7 i}$ & & \\
\hline 1 & 187.45647 & 0 & 0.015766 & 1.02442 & 0 & 0 & 0 & 0 & \multirow{4}{*}{0.9998} \\
\hline $2-$ & $-2.86717 e-15$ & 19.19598 & 6.36778 & 0.45949 & 0 & 0 & 0 & 0 & \\
\hline 3 & 49.69459 & 0.31415 & 0.19098 & 0.75487 & 54.47474 & -0.46131 & 1.02025 & -2.13633 & \\
\hline 4 & 0.053377 & 0.78235 & 0 & 0 & 10.08538 & 0.18957 & $\mid 0.95059$ & 3.17357 & \\
\hline 5 & $1.07244 \mathrm{e}-15$ & 11.07103 & 0.088055 & 1.72617 & \begin{tabular}{|l|}
9.17274 \\
\end{tabular} & $-9.15640 e-5$ & 2.14584 & 3.11366 & 0.6636 \\
\hline 6 & $3.41389 \mathrm{e}-26$ & 20.04463 & 0.22012 & 1.14113 & 1.43509 & 0.0013114 & 1.34194 & 3.30927 & 0.4248 \\
\hline 7 & $1.52358 \mathrm{e}-12$ & 10.48999 & 1.74813 & 0.54248 & 9.55074 & 0.025224 & 1.17920 & -1.00776 & 0.4456 \\
\hline 8 & -0.00033542 & 8.34100 & 1.00131 & 0.99842 & 21.16355 & -0.95067 & 0.99945 & 0.57709 & 0.5181 \\
\hline \begin{tabular}{l|l}
9 \\
\end{tabular} & \begin{tabular}{|l|}
-863.40909 \\
\end{tabular} & 1.82258 & 1.53637 & 1 & \begin{tabular}{|l|}
1.00848 \\
\end{tabular} & $-3.04624 e-5$ & 1 & \begin{tabular}{|l|}
1.54239 \\
\end{tabular} & 0.4865 \\
\hline $10^{\prime}$ & 7.31771e-18 & 11.88873 & 0.0034026 & 1.96387 & 1.44349 & $-4.49663 e-5$ & 1 & -1.98152 & 0.2796 \\
\hline 11 & \begin{tabular}{|l|}
-1.07789 \\
\end{tabular} & 4.20627 & 6.21807 & 0.26549 & 4.23357 & 0.0078348 & 1.08874 & 5.08714 & 0.3259 \\
\hline $12 !$ & 9.60536e-11 & 6.91254 & 0.038913 & 1.23737 & 9.35351 & 0.00014587 & 1.82975 & & \\
\hline 13 & $5.37538 \mathrm{e}-8$ & 4.74921 & 0.071209 & 1 & 3.42746 & -0.0043890 & 0.89799 & -3.68623 & 0.1456 \\
\hline 14 & $1.30443 \mathrm{e}-12$ & 9.24012 & 0.13243 & 1.07020 & 2.32881 & 630 & 0.98843 & -0.62752 & 0.5356 \\
\hline 15 & $4.82354 \mathrm{e}-8$ & 5.68872 & 63 & 1.01363 & 1.72858 & -0.000 & 1.21021 & -4.08995 & 0.3219 \\
\hline 16 ? & $3.50333 \mathrm{e}-23$ & 14.58853 & 0.083976 & 1.15082 & 1.81299 & 0.012097 & 0.98185 & -0.018239 & 0.3058 \\
\hline 17 & $3.87293 \mathrm{e}-13$ & 9.06866 & 0.015213 & 1.58686 & 1.07257 & 0 & \begin{tabular}{|l|}
0 \\
\end{tabular} & -0.64405 & 0.3678 \\
\hline 18 & $5.12457 \mathrm{e}-12$ & 6.05281 & & 0.99107 & 3.10420 & 0.010680 & 0.99806 & -3.73578 & 0.3723 \\
\hline 19 & 0.14564 & 3.99664 & 0.93140 & 0.94538 & 1.85639 & 76 & 1.45693 & 4.12283 & 0.3757 \\
\hline 20 & $2.04922 \mathrm{e}-23$ & 14.97220 & 0.18274 & 1 & 2.60596 & -0.003 & 0.80691 & -2.96192 & 0.2591 \\
\hline 21 & -0.15891 & 0.97242 & 0.18606 & 0.92004 & 0.98795 & & 1.01703 & 1.38818 & 0.2522 \\
\hline $22-$ & $-1.39274 \mathrm{e}-12$ & 8.75823 & 0.021 & 1.50709 & 1.30011 & 0.0014 & 0.90273 & -5.45653 & 4930 \\
\hline 23 & 0.028455 & 0.40270 & 0.01 & 0.99422 & \begin{tabular}{|l|}
8.69369 \\
\end{tabular} & 3464 & 1.02153 & \begin{tabular}{|l|}
0.37412 \\
\end{tabular} & 0.2694 \\
\hline 24 & -0.00058826 & 0.97035 & 0.007 & 1.01483 & 10.14827 & -0.0032763 & 1.00979 & -2.65294 & 0.1831 \\
\hline 25 & -0.0056998 & 1.14550 & 0.031629 & 1.00063 & \begin{tabular}{|l|}
1.43941 \\
\end{tabular} & -0.00085457 & 1.00038 & -1.96137 & 0.2064 \\
\hline 26 & 0.0013499 & 2.03838 & 0.048504 & 0.99159 & 880.95021 & -2.31479 & 1.03180 & -1.59842 & 0.2603 \\
\hline 27 & -0.0056320 & 0.44424 & 0.040701 & 0.30679 & 35.92776 & 0.0097363 & 1.07486 & -2.04222 & 0.4429 \\
\hline 28 & $1.34053 \mathrm{e}-8$ & 4.52015 & 0.054645 & 1 & 1.16571 & $7.05509 \mathrm{e}-8$ & 1 & 5.09377 & 0.1494 \\
\hline 29 & $1.85759 \mathrm{e}-8$ & 5.58343 & 0.090057 & 1.08254 & 1.03245 & 0 & 0 & -2.69634 & 0.1859 \\
\hline 30 & $2.58645 \mathrm{e}-9$ & 5.50119 & 0.035984 & 1.18142 & 1.94091 & 0 & 0 & 1.94624 & 0.2759 \\
\hline 31 & $8.06312 \mathrm{e}-7$ & 4.19441 & 0.079413 & 1.00317 & 1.98118 & 0.0017475 & 0.93735 & -2.20480 & 0.3432 \\
\hline 32 & \begin{tabular}{|l|}
$-7.45700 \mathrm{e}-9$ \\
\end{tabular} & 5.33886 & 0.069677 & 1.03075 & 1.73125 & 0 & 0 & 3.61635 & 0.4006 \\
\hline 33. & -0.00084455 & 4.02220 & 0.40364 & 1.01459 & 0.76601 & 0.0063077 & 0.89039 & 3.73975 & 0.1438 \\
\hline 34 & $9.36029 \mathrm{e}-29$ & 17.65442 & 0.095160 & 1.14343 & 1.45927 & 0 & 0 & 5.66312 & 0.4373 \\
\hline 35 & -0.0010656 & 3.45706 & 0.35083 & 0.97115 & 36.38705 & -1.44675 & 0.99905 & 0.23182 & 0.1588 \\
\hline 36 & $6.52400 \mathrm{e}-5$ & 1.96654 & 0.028439 & 0.98249 & 48.61980 & 0.11573 & 1.01988 & -1.20584 & 0.1794 \\
\hline 37 & $6.68585 \mathrm{e}-10$ & 5.28134 & 0.035821 & 1.11217 & 16.30376 & 0.025434 & 0.95719 & 0.15819 & 0.1899 \\
\hline 38 & $-1.13750 \mathrm{e}-7$ & 3.85473 & 0.053877 & 1.00058 & \begin{tabular}{|l|}
1.13743 \\
\end{tabular} & $1.87992 \mathrm{e}-5$ & 0.95411 & 4.90757 & 0.1921 \\
\hline 39 & -0.0023357 & 1.13181 & 0.024165 & 1.02068 & 0.60264 & 0 & 0 & 0.53165 & 0.1875 \\
\hline 40 & $3.89889 \mathrm{e}-5$ & 2.62232 & 0.039979 & 1.06737 & 1.38190 & 0.0013963 & 1.03180 & 2.18479 & 0.2361 \\
\hline
\end{tabular}




\begin{tabular}{|c|c|c|c|c|c|c|c|c|c|}
\hline \multirow{3}{*}{$i$} & \multicolumn{8}{|c|}{ Асимметричный вейвлет $y_{i}=a_{1 i} x^{a_{2 i}} \exp \left(-a_{3 i} x^{a_{4 i}}\right) \cos \left(\pi x /\left(a_{5 i}+a_{6 i} x^{a_{7 i}}\right)-a_{8 i}\right)$} & \multirow{3}{*}{$\begin{array}{c}\text { Коэळ. } \\
\text { Корр. } \\
r\end{array}$} \\
\hline & \multicolumn{4}{|c|}{ Амплитуда (половина) колебания } & \multicolumn{3}{|c|}{ Полупериод колебания } & \multirow{2}{*}{\begin{tabular}{|c|} 
Сдвиг \\
$a_{8 i}$
\end{tabular}} & \\
\hline & $a_{1 i}$ & $a_{2 i}$ & $a_{3 i}$ & $a_{4 i}$ & $a_{5 i}$ & $a_{6 i}$ & $a_{7 i}$ & & \\
\hline 41 & $\mid 0.00016817$ & 1.38412 & 0.010113 & \begin{tabular}{|l|}
1.02557 \\
\end{tabular} & 14.96649 & -0.0024032 & \begin{tabular}{|l|}
0.99814 \\
\end{tabular} & \begin{tabular}{|l}
-0.94366 \\
\end{tabular} & 0.3623 \\
\hline 42 & $-3.82637 e-14$ & 8.63411 & 0.10167 & 1.03121 & 1.08559 & 0 & 0 & -3.88097 & 0.2513 \\
\hline 43 & 0.00011879 & 1.85550 & 0.027082 & 0.95935 & 7.54963 & 0.0027992 & $\mid 0.95666$ & -0.43611 & 0.4329 \\
\hline 44 & $9.68489 \mathrm{e}-33$ & 20.90744 & 0.25851 & 0.99492 & 6.40671 & 0.0020495 & \begin{tabular}{|l|}
0.99096 \\
\end{tabular} & -1.86079 & 0.2380 \\
\hline 45 & $-2.30031 \mathrm{e}-9$ & 4.95106 & 0.059632 & 1.01305 & 0.99285 & 0 & 0 & -3.83652 & 0.1092 \\
\hline 46 & $-1.43738 \mathrm{e}-19$ & 11.43055 & 0.048507 & 1.19292 & 1.21550 & 0 & 0 & -1.66594 & 0.2883 \\
\hline 47 & -0.45960 & 0 & 1.82767 & 1 & 1 & 0 & 0 & 0 & 0.2946 \\
\hline 48 & -0.00024786 & 1.32334 & 0.023072 & 0.94123 & 5.09631 & -0.00040752 & 0.85883 & -0.83556 & 0.1322 \\
\hline 49 & $8.99028 \mathrm{e}-7$ & 2.15168 & 0.0042998 & 1.15494 & 11.49795 & 0.010105 & 1.08276 & 4.18528 & 0.2614 \\
\hline 50 & -0.011742 & 0.38674 & 0.028314 & 0.83083 & 6.87383 & -0.00038171 & 1.06371 & 0.17925 & 0.2473 \\
\hline 51 & $2.59746 \mathrm{e}-7$ & 5.26440 & 0.59451 & 0.65770 & 4.17835 & -0.0066660 & 1.06098 & -1.78601 & 0.4172 \\
\hline 52 & $-1.75985 e-10$ & 5.80594 & 0.12967 & 0.87329 & 5.30049 & -0.009 & 0.95337 & -5.23367 & 0.3337 \\
\hline 53 & $6.65592 \mathrm{e}-7$ & 3.98525 & 0.10288 & \begin{tabular}{|l|}
0.96064 \\
\end{tabular} & 2.02107 & -0.00080466 & 1.15826 & -1.24667 & 0.2234 \\
\hline 54 & $3.72425 \mathrm{e}-14$ & 6.65693 & 0.037324 & 1.02957 & 20.20937 & -0.026810 & 1.00282 & -0.32478 & 0.2392 \\
\hline 55 & $-9.37192 \mathrm{e}-26$ & 15.66493 & 0.17873 & 0.99482 & 2.28301 & 0.0020233 & 0.99114 & 0.41197 & 0.2783 \\
\hline 56 & $7.84977 \mathrm{e}-10$ & 4.21985 & 0.020785 & 1.08376 & 8.93901 & -0.00098169 & 0.76531 & 0.88723 & 0.1225 \\
\hline 57 & $2.83725 \mathrm{e}-8$ & 12.77958 & 1.52999 & 0.98132 & 3.11229 & -0.058770 & 1.04994 & -1.99784 & 0.1430 \\
\hline 58 & -0.00045428 & \begin{tabular}{|l|}
1.41783 \\
\end{tabular} & \begin{tabular}{|l|}
0.012935 \\
\end{tabular} & 1.16869 & 1.26180 & 0 & \begin{tabular}{|l|}
0 \\
\end{tabular} & -3.70888 & 0.2307 \\
\hline 59 & $-9.32587 \mathrm{e}-31$ & 16.88012 & 0.0031489 & 1.77460 & 1.33613 & 0 & 0 & 1.82689 & 0.3891 \\
\hline 60 & $2.49897 \mathrm{e}-16$ & 8.96865 & 0.077029 & 1.03676 & 1.60464 & 0 & 0 & -0.52975 & 0.1586 \\
\hline 61 & $2.16655 \mathrm{e}-6$ & 3.14867 & 0.054222 & 0.99218 & 2.73305 & -0.0034324 & 0.99463 & -5.73334 & 0.2578 \\
\hline 62 & $6.43493 \mathrm{e}-16$ & 8.23472 & 0.072136 & 1.00020 & 2.00935 & $-6.94312 e-5$ & 0.99390 & 1.28144 & 0.1271 \\
\hline 63 & $-1.17140 \mathrm{e}-6$ & 3.52040 & 0.36664 & $\mid 0.62550$ & 3.91849 & 0.0036856 & 0.60103 & 0.26153 & 0.2313 \\
\hline 64 & $2.05422 \mathrm{e}-5$ & 2.02777 & 0.027274 & 0.99936 & 6.05465 & 0.00017954 & 0.95161 & -0.85400 & 0.1801 \\
\hline 65 & $-7.00112 \mathrm{e}-9$ & 4.40942 & 0.057036 & 1 & 2.08713 & 0.00010343 & 1 & -0.76273 & 0.1391 \\
\hline 66 & $2.02117 \mathrm{e}-7$ & 3.20231 & 0.037196 & 1 & 2.50860 & $8.60951 \mathrm{e}-5$ & 1 & -2.78455 & 0.1327 \\
\hline 67 & -0.0035004 & 0.34258 & 0.0071469 & 1.01304 & 4.26938 & 0.019883 & 0.79487 & 2.41671 & 0.1781 \\
\hline 68 & $9.02565 \mathrm{e}-12$ & 5.59058 & 0.041185 & 1.02190 & 6.71346 & 0.0010622 & 1.14142 & 0.42619 & 0.1986 \\
\hline 69 & $5.41978 \mathrm{e}-15$ & 10.17015 & 0.19950 & 0.99993 & 2.90571 & 0.00027493 & 1.00073 & 1.67678 & 0.2587 \\
\hline 70 & $4.09583 \mathrm{e}-6$ & 3.93386 & 1.02013 & 0.49660 & 19.00624 & 0.0060140 & 1.40598 & 3.06411 & 0.1764 \\
\hline 71 & 0.038404 & 0.93426 & 0.51485 & 0.63866 & 1.04372 & 0.0074877 & 0.74551 & -0.14214 & 0.2010 \\
\hline 72 & -0.00011612 & 1.37746 & 0.016233 & 1.01436 & 10.92242 & -0.0010024 & 0.91377 & -0.56420 & 0.2195 \\
\hline
\end{tabular}

Из данных таблицы 5 видно, что первый член является законом экспоненциального спада и показывает естественное распределение лесных земельных участков. Вторая составляющая по биотехническому закону изза отрицательного знака характеризует антропогенное влияние на измельчение земельных участков.

Со второго по 72-й члены все являются конечномерными вейвлетами (кроме №47, который показывает переход из-за отсутствия «эффекта встряски» между отдельными членами). Таким образом, все колебательные возмущения являются временными в пределах лесничества. Поэтому они показывают предысторию структурных изменений в лесных массивах. В принципе для каждой волны, если бы мы знали эвристическое описание истории лесопользования, можно найти причину её появления и угасания.

Наличие волн показывает эффект колебательной адаптации лесов. 
Полный вейвлет анализ и верификация. Проверить относительную погрешность можно в программной среде Excel прямыми расчетами по остаткам после CurveExpert-1.40.

Всего 2806 лесных земельных участков.

Для модели из 72 членов при площади $S \geq 0.4$ га относительная погрешность $\leq 0.91 \%$, при 0.3 га $1.75 \%$, при 0.2 га $0.34 \%$, а при 0.1 га (86 точек или $3,06 \%$ ) максимальная относительная погрешность равна $10,62 \%$.

Погрешность измерения равна \pm 0.05 га, так как цена деления при записи значений площади по исходным данным имеет интервал 0.1 га.

Тогда из 2806 ЛЗУ только 18 точек (или 0.64\%) по остаткам превышают погрешность измерения.

Поэтому полный вейвлет анализ можно считать завершенным.

Модель (6) с коэффициентом корреляции 0.9998 была получена по вычислительным возможностям программно среды CurveExpert-1.40, затем каждая из 5-72 составляющих идентифицировалась по уравнению (2) обособленно. Рассмотрим далее остатки и относительные погрешности после формулы (6).

От 187 до 0.6 га площади лесных земельных участков с относительной погрешностью статистического моделирования более 5\% находится 19 точек из общего количества 2228 участков $(0.85 \%)$. С дальнейшим снижением площади резко возрастает погрешность модели (6): при 0.5 га погрешность равна 7.64\%; при 0.4 га - 12.14\%; при 0.3 га - 19.81 га; при 0.2 га - 35.44\%; при 0.1 га - 82.85 га. Тогда 597 точек (или $21.28 \%$ из общего количества 2806 участков) по модели (6) будут превышать 5\%-й предел относительной погрешности.

Таким образом, модель (6) с репрезентативностью $100 \times 2228 / 2806=$ $79.40 \%$ будет с высокой точностью будет описывать ранговое распределение лесных земельных участков от 187 до 0.5 га.

Заключение. Площадь лесных земельных участков является первичным важнейшим показателем, однако он до сих пор, например, в сравнении с таксационными показателями лесных выделов и лесных модельных и учетных деревьев, не применяется в составлении различных математических моделей. В данной статье показано, что эта площадь является очень точным с позиций погрешности измерений $( \pm 0.5$ га) и весьма информативным по ранговым распределениям параметром лесных массивов. При этом деление на лесные квартала - это только человеческое изобретение, поэтому нами предлагается структурной единицей принимать только территорию лесничества. Основной частью любого лесничества являются лесные земельные участки, часть из которых на момент проведения измерений являются также и лесными выделами, то есть лесными земельными участками, покрытые лесными деревьями.

На примере Керебелякского лесничества удалось показать, что лесные земельные участки имеют фрактальную структуру. Для этого нужно 
будет 72 вейвлета разделить на отдельные фракталы.

Выявленные 72 члена общей модели типа (2) позволяют с максимальной относительной погрешностью до $1.75 \%$ заменить распределение лесных земельных участков от 0.2 га и больше. При участках площадью 0.1 га относительная погрешность равна $10.62 \%$, поэтому этот размер показывает чрезмерное дробление лесного массива в прошлом разными рубками. Первые четыре члена этой модели дают для ряда распределения от 0.6 га и более с коэффициентом корреляции 0.9997 и относительной погрешностью до $5 \%$.

Таким образом, лесничество имеет закономерно распределенные по рангам лесные земельные участки по площади. По ранговым распределениям можно будет сравнивать между собой отдельные лесничества у разных лесных предприятий. По четырем лесничествам национального парка «Марий Чодра» можно будет определять коэффициенты качества лесного предприятия и затем сравнивать между собой отдельные лесные предприятия как субъекта федерации, так и всей нашей страны.

\section{Список литературы}

1. Мазуркин П.М. Биокаркас территории: учеб. пос. с грифомУМО РАЕ. Йошкар-Ола: ПГТУ, 2016. 146 с. Doi 10.18411/d-2016-088.

2. Мазуркин П.М. Коррелятивная вариация: учеб. пос. с грифом УМО РАЕ. Йошкар-Ола: ПГТУ, 2016. 116 с. Doi 10.18411/d-2016-095.

3. Мазуркин П.М. Поведение сосняков как эргатической системы леса (по данным J. Ilvessalo из книги А.К. Каяндера о лесах Южной Финляндии). Йошкар-Ола: ПГТУ, 2016. 10c. Doi 10.18411/d-2016-096.

4. Мазуркин П.М. Ранговые распределения параметров кривых высот по дендрорядам разновозрастного сосняка Сибири. Йошкар-Ола: ПГТУ, 2016. 10c. Doi 10.18411/d-2016-123.

5. Мазуркин П.М. Статистическая идентификация рядов динамики // Вестник мировой науки. Серия «Экономика». №1 . 2016. С. 79-96. doi 10.18411/jos-2016-econ-1-05.

6. Мазуркин П. М. Статистическая эконометрика: учебное пособие. ЙошкарОла: МарГТУ. 2006. 376 с.

7. Мазуркин П.М. Экологический баланс территории: учеб. пос. с грифом УМО РАЕ. Йошкар-Ола: ПГТУ, 2016. 148c. Doi 10.18411/d-2016-087.

8. Мазуркин П.М. Экономико-статистическое моделирование: учеб. пос. с грифом УМО РАЕ. Йошкар-Ола: Поволжский ГТУ, 2016. 276 с.

9. Mazurkin P.M. Invariants of the Hilbert Transform for 23-Hilbert Problem, Advances in Sciences and Humanities. Vol. 1, No. 1, 2015, pp. 1-12. doi: 10.11648/j.ash.20150101.11

10. Mazurkin P.M. Method of identification. (2014). International Multidisciplinary Scientific GeoConference Surveying Geology and Mining Ecology Management, SGEM, 1 (6), pp. 427-434. URL: https://www.scopus.com/inward/record.uri?eid=2-s2.084946541076\&partnerID=40\&md5=72a3fcce31b20f2e63e4f23e9a8a40e3

11. Mazurkin P.M. The invariants of the Hilbert transform data wavelet analysis. Yoshkar-Ola: VSUT, Volga Tech, 2016. 21 p. Doi 10.18411/d-2016-159.

12. Mazurkin P.M. Wavelet Analysis Statistical Data. Advances in Sciences and Humanities. Vol. 1, No. 2, 2015, pp. 30-44. doi: 10.11648/j.ash.20150102.11. 